\title{
La transposición de las directivas de contratación pública en España: una primera valoración de sus principales novedades ${ }^{1}$
}

\author{
José María Gimeno Feliu \\ Universidad de Zaragoza \\ gimenof@unizar.es
}

\begin{abstract}
NOTA BIOGRÁFICA
José María Gimeno Feliu es Catedrático de Derecho Administrativo (Facultad de Derecho de la Universidad de Zaragoza). Presidente del Tribunal Administrativo de Contratos Públicos de Aragón (desde marzo de 2011). Miembro del Consejo Asesor del MInisterio de Fomento (julio 2015). Director de la Cátedra de Derecho Local de Aragón desde marzo de 2010 a diciembre de 2012. Director de la Catedra Estrategia e Innovación en contratación publica en el ámbito de la salud (UNIZAR), desde junio de 2016.
\end{abstract}

\section{SUMARIO}

I. UNA BREVE REFERENCIAA LOS PRINCIPALES OBJETIVOS DE LA REFORMA EUROPEA DE CONTRATACIÓN PÚBLICA. II. LAS PRINCIPALES NOVEDADES DE LA LEY 9/2017, DE CONTRATOS DEL SECTOR PÚBLICO: UNA VISION «RÁPIDA». III. CONCLUSIONES.

\section{UNA BREVE REFERENCIA A LOS PRINCIPALES OBJETIVOS DE LA REFORMA EUROPEA DE CONTRATACIÓN PÚBLICA}

El análisis de la nueva regulación española de contratos del sector público exige conocer las condiciones exigidas por la necesaria incorporación de las Directivas de cuarta generación de contratación pública que contienen una novedosa regulación en clave de visión estratégica².

Las Directivas 23, 24 y 25 de 2014, de 26 de febrero, respectivamente, «de cuarta generación», vienen a superar la lógica «armonizadora» de sus predecesoras ${ }^{3}$. Y optan, como señala G. A. BENACCHIO por

\footnotetext{
1 Este estudio se enmarca en el Proyecto de investigación concedido por Ministerio de Economía y Competitividad titulado "La nueva regulación de la contratación pública: Hacia un nuevo sistema de gobernanza pública y de actuación de los poderes públicos" DER2015-67102-C2-1-P, cuyo IP es el autor. El mismo será objeto de publicación por la Revista Documentación Administrativa.

2 Lo que queda reflejado expresamente en la Estrategia Europa 2020, que indica que la contratación pública es una herramienta principal para el cumplimiento de esos objetivos. Cuestión sobre la que insiste la reciente la Comisión Europea "Conseguir que la contratación pública funcione a Europa y para Europa" (3 de octubre de 2017, COM (2017) 572 final) al insistir en la idea de una estrategia de contratación pública, para lo que establece el marco político general y define prioridades claras para mejorar la contratación en la práctica y dar apoyo a las inversiones en el seno de la UE.

${ }^{3}$ Sobre el contenido de estas Directivas me remito a: J. M. GIMENO FELIU, El nuevo paquete legislativo comunitario sobre contratación pública. De la burocracia a la estrategia. (El contrato público como herramienta del liderazgo institucional de los poderes públicos), Aranzadi, Cizur Menor, 2014; J. A. MORENO MOLINA, "La cuarta generación de Directivas de la Unión Europea sobre contratos Públicos", en libro colectivo Observatorio de los Contratos Públicos 2012, Aranzadi, Cizur Menor, 2013, págs. 115 a 163; J. A. MORENO MOLINA, y P. DOMÍNGUEZ ALONSO, "El nuevo derecho de la Unión Europea sobre contratación pública", en la obra colectiva La contratación pública a debate: presente y futuro, Civitas-Thomson, Cizur Menor, 2014, págs. 139-164; M. M. RAZQUIN, "Las nuevas Directivas sobre contratación pública de 2014: aspectos clave y propuestas para su transformación en España", RAP, núm. 196, 2015, págs. 97-13 y. De especial interés, en tanto se apuntan las líneas estratégicas de la reforma, es el trabajo de A. RUIZ DE CASTAÑEDA y M. A. BERNAL BLAY, "La contratación pública y el Derecho comunitario. Cuestiones pendientes", en libro colectivo Observatorio de los Contratos Públicos 2010, Civitas, Cizur Menor, 2011, págs. 23 a 42. Sobre los principios aplicables a esta materia, por todos, me remito al trabajo de J. A. MORENO MOLINA, "El sometimiento de todos los contratos públicos a los principios generales
} 
prescindir del establecimiento de reglas excesivamente rígidas e invasivas en favor de la promoción de los objetivos de simplificación y eficiencia 4 . Son textos, por lo demás, de mayor «densidad» que sus predecesoras y se siguen observando parecidas deficiencias técnicas que complican la correcta adaptación de sus reglas a las normas nacionales ${ }^{5}$. Pero a pesar de todo, en mi opinión, suponen un importante avance pues han permitido replantear el modelo teórico y práctico de la legislación de contratación en España ${ }^{6}$.

La revisión (que no mera actualización) de las Directivas sobre contratación pública de 2014 se inscribe en un programa de conjunto cuyo objetivo es una modernización en profundidad del sistema público de contratación en la Unión Europea para ser más eficientes y diseñar políticas que permitan un mayor crecimiento en un contexto de globalización económica ${ }^{7}$. Lo que no significa una liberalización "sin restricciones» a la política de contratación pública. Basta recordar el contenido de la Resolución del Parlamento Europeo, de 12 de mayo de 2011, sobre la igualdad de acceso a los mercados del sector público en la UE y en terceros países, y sobre la revisión del marco jurídico de la contratación pública, incluidas las concesiones (publicada en el DOUE 7 de diciembre de 2012), -se insiste en los comentarios incluidos en su Resolución del 18 de mayo de 2010 sobre nuevos aspectos de la política de contratación pública-, en la que, si bien se opone enérgicamente a las medidas proteccionistas en el ámbito de la contratación pública a escala mundial, cree firmemente en el principio de reciprocidad y proporcionalidad en dicho ámbito y, en este sentido, pide a la Comisión que realice un análisis detallado de las posibles ventajas y problemas asociados con la imposición de restricciones proporcionadas y específicas al acceso a determinados sectores de los mercados de contratación pública de la UE, una evaluación de impacto que analice cuándo pueden aplicarse, así como una evaluación del fundamento jurídico que requeriría este instrumento, para aquellos socios comerciales que se benefician de la apertura del mercado de la UE pero que no han demostrado intención alguna de abrir sus mercados a las empresas de la UE, alentando a la vez a los socios de la UE a que ofrezcan a las empresas europeas condiciones de reciprocidad y proporcionales en el acceso al mercado, antes de proponer cualquier otro nuevo texto en el ámbito de la contratación pública. Asimismo, el Parlamento solicita a la Comisión que evalúe los problemas asociados con las ofertas extraordinariamente bajas y que proponga soluciones adecuadas; recomienda a las autoridades contratantes que faciliten información temprana y suficiente a otros licitadores en caso de ofertas anormalmente bajas, con el fin de que puedan valorar si existen motivos para iniciar un procedimiento de recurso; y considera urgente que la UE alcance una mayor coherencia entre su política comercial exterior común y la práctica existente en los Estados miembros de aceptar ofertas excepcionalmente bajas de empresas cuyos países de origen no son signatarios del Acuerdo de Contratación Pública (ACP), en perjuicio de empresas de la Unión Europea y de las normas laborales, sociales y medioambientales de los Estados miembros de la Unión ${ }^{8}$.

de contratación" en el Liber amicorum Tomás-Ramón Fernández, Thomson, Pamplona, 2012, pág. 3.429 y ss. del tomo II. Una visión crítica sobre los objetivos de estas Directivas puede verse en el estudio del profesor J. SANTAMARÍA PASTOR, "Contratos del sector público y derecho de la Unión", RAP, núm. 200, 2016, págs. 83-102.

4 Vid. "Verso le Direttive di quarta generazione", en G. A. BENACCHIO-M. COZZIO, Gli appalti pubblici: tra regole europee e nazionali, Egea, Milano, pág. 8.

5 Especialmente crítico, también con el Derecho de la Unión Europea, se manifiesta J. SANTAMARÍA PASTOR, "La constante e interminable reforma de la normativa sobre contratación pública", Revista Española de Derecho Administrativo, número 159, 2013, pág. 35.

6 Me remito a mi monografía El nuevo paquete legislativo comunitario sobre contratación pública. De la burocracia a la estrategia. (El contrato público como herramienta del liderazgo institucional de los poderes públicos), Aranzadi, Cizur Menor, 2014.

7 El "Informe de evaluación: impacto y eficacia de la legislación comunitaria sobre contratación pública" (http://ec.europa.eu/ internal market/publicprocurement/modernising rules/evaluation/index en.htm\#maincontentSec1) recoge las opiniones y recomendaciones de más de seiscientos profesionales sobre la efectividad de las actuales directivas que rigen la contratación en organismos públicos. El informe destaca que las directivas sobre contratación pública han fomentado la apertura y la transparencia provocando que la competencia se haya intensificado. Esto se ha traducido en un ahorro de costes o inversión pública adicional que se cuantifica en 20.000 millones de euros, un cinco por ciento de los 420.000 millones de euros que se licitan anualmente a escala europea en contratos públicos. También recoge el deseo unánime de recortar, agilizar y flexibilizar los trámites burocráticos. Este aspecto resulta fundamental para las pequeñas y medianas empresas (PYME) que actualmente sufren completando la cantidad de exigencias administrativas que obligan los procesos de licitación. Este análisis ha servido de punto de partida para la revisión de las directrices que se acometió a finales del pasado año. Con ella se pretende mantener una política equilibrada que preste apoyo a la demanda de bienes, servicios y obras que sean respetuosos con el medio ambiente, socialmente responsables e innovadores, ofreciendo además a las autoridades adjudicadoras unos procedimientos más sencillos y flexibles y que garanticen un acceso más fácil a las empresas, particularmente a las PYME.

8 Con fecha 23 de marzo de 2013 la Comisión Europea presentó la propuesta para la decisión Consejo relativa a la conclusión formal del Protocolo que modifica el Acuerdo sobre Contratación Pública (ACP), el único acuerdo legalmente vinculante en la OMC relativa a la contratación pública. Por otro lado, en relación con la modernización de la política de contratación pública de la UE, apoya la petición de que se clasifiquen por prioridades las cuestiones tratadas en el Libro Verde y, en este sentido, pide a la Comisión que 
Por otra parte, en la lógica de una correcta transposición de las Directivas europeas de contratación, no puede desconocerse la existencia de un derecho pretoriano que vertebra el sistema ${ }^{9}$. En una materia tan sensible y a la vez tan cambiante, existe una importante «fuente de derecho», ya que la jurisprudencia del TJUE de la Unión Europea ha conformado un sólido y coherente derecho pretoriano, que sirve de fuente interpretativa y que limita aquellas opciones que puedan contravenir las reglas de la Unión Europea. De hecho, son, en la práctica, una especie de codificación, que dota de coherencia y seguridad jurídica al sistema (tanto a nivel comunitario como de aplicación práctica en los ordenamientos nacionales). Así, los conceptos «comunitarios» deben ser interpretados de conformidad con la doctrina fijada por el TJUE ${ }^{10}$. Doctrina que debe ser conocida y respetada por los distintos intérpretes o aplicadores de las reglas de la contratación pública, lo que limita interpretaciones o prácticas nacionales que pretendan una visión «local» de las normas de contratos públicos ${ }^{11}$. Existe, en consecuencia, una «armonización» a escala de doctrina TJUE que impide que se laminen los principios de la contratación pública y que exige una interpretación funcional (y no formal) ${ }^{12}$.

Finalmente, para una correcta contextualización de los cambios de la legislación nacional resultan convenientes, aun de forma sucinta, recordar algunas premisas de especial interés. La primera, que el objetivo principal de esta normativa comunitaria garantizar la eficiencia de los fondos públicos. A tal fin la obligación de transparencia es un instrumento principal que ha de garantizar, en beneficio de todo licitador potencial, una publicidad adecuada que permita abrir a la competencia el mercado de servicios y controlar la imparcialidad de los procedimientos de adjudicación (STJUE de 7 e diciembre de 2000, ARGE). Este principio encuentra su principal manifestación práctica, en primer lugar, a través de una adecuada publicidad de los contratos adjudicables en el Diario Oficial de la Unión Europea (DOUE) de las distintas ofertas de contratos públicos, presentando la misma una doble faceta: a) como mecanismo de fiscalización de la Administración, la publicidad constituye una magnífica ayuda para el juego limpio en la vida administrativa y una oportunidad de control a disposición de los administradores y de los candidatos contractuales; b) como medio de promoción de la concurrencia entre los agentes económicos implicados. Publicidad que debe generar competencia o concurrencia empresarial, como recuerda la STJUE de 15 de octubre de 2009, (Acoset), al afirmar que los principios de igualdad de trato y de no discriminación por razón de la nacionalidad implican en particular una obligación de transparencia, que permite que la autoridad pública concedente se asegure de que tales

examine en primer lugar las cuestiones de la simplificación de las normas, el acceso equilibrado a los mercados del sector público, y la mejora del acceso de las PYME, y que emprenda como un segundo paso la revisión de la contratación pública y las concesiones, con el fin de obtener la necesaria y completa participación, no solo del Parlamento Europeo y los Estados miembros, sino también de los ciudadanos y las empresas. En fecha 7 de marzo de 2014 se ha publicado en el DOUE el Protocolo por el que se modifica el Acuerdo sobre Contratación Pública, hecho en Marrakech el 15 de abril de 1994. En concreto, reemplaza el Preámbulo, los artículos I a XXIV y los Apéndices del Acuerdo de 1994, por las disposiciones establecidas en su anexo.

9 Vid. J. M. GIMENO FELIU, “La «codificación» de la contratación pública mediante el derecho pretoriano derivado de la jurisprudencia del TJUE", REDA, núm. 172, 2015, págs. 81-122. También I. GALLEGO CÓRCOLES, "Las relaciones «contractuales» entre entes públicos no sometidas a la Directiva 2014/24/UE sobre contratación pública”, en libro colectivo dirigido por M. ALMEIDA e I. MARTíN, La nueva contratación pública, Actas del I Congreso de la Red Internacional de Derecho Europeo (Toledo, 13 y 14 noviembre de 2014 ), págs. 111-116. En relación con el impacto de la jurisprudencia en el proceso de creación de las reglas sobre contratación pública, vid. COZZIO M., "La función de la jurisprudencia en el proceso de europeización de las reglas de contratación pública”, en GIMENO FELIU (Dir.), Observatorio de Contratos Públicos 2012, Civitas, 2013; págs. 89-116. Más recientemente, el libro colectivo (A. BENACHIO, M. COZZIO y F. Titomanlio) I contratti pubblici nella giurisprudenza dell'Unione Europea, Tomo I, publicación del Osservatorio di Diritto comunitario e nazionale sugli appallti pubblici. Universidad de Trento, 2016.

10 Vid. CHINCHILLA MARÍN, C.: "La jurisprudencia del TJUE sobre contratos públicos (I). Ámbito subjetivo y objetivo de aplicación de las Directivas", en la obra colectiva El Derecho de los contratos públicos en la Unión Europea y sus Estados miembros, Lex Nova, Valladolid, 2011, págs. 33-79; y M. SÁNCHEZ MORÓN, "La jurisprudencia del TJUE sobre contratos públicos (II). Adjudicación de los contratos y recursos en materia de contratación", en la obra colectiva El Derecho de los contratos públicos en la Unión Europea y sus Estados miembros, Lex Nova, Valladolid, 2011, págs. 81-102.

11 Para conocer como se ha realizado la transposición de la normativa de contratación pública en los distintos Estados miembros es de especial interés la excelente monografía anteriormente citada, dirigida por M. SÁNCHEZ MORÓN: El Derecho de los contratos públicos en la Unión Europea y sus Estados miembros, Lex Nova, Valladolid, 2011.

12 Como explica muy bien C. CHINCHILLA MARÍN (“La jurisprudencia del TJUE sobre contratos públicos...”, ob. cit., págs. 38-39), la interpretación del derecho comunitario de los contratos públicos debe respetar tres reglas: a) se debe realizar desde la lógica del derecho comunitario y no desde los derechos nacionales, b) la interpretación debe tener un alcance funcional/finalista y c) debe practicarse una interpretación amplia del derecho comunitario cuando se pretende determinar, en clave positiva, el ámbito de aplicación de esta normativa y, por el contrario, estricta, si se trata de «excluir» su aplicación. Es necesaria, en palabras de R. ALONSO GARCíA, una interpretación de la norma nacional conforme al Derecho europeo, "La interpretación del Derecho de los Estados conforme al Derecho Comunitario: las exigencias y los límites de un nuevo criterio hermenéutico", Revista Española de Derecho Europeo, núm. 28, 2008, págs. 385-410. También J. M. GIMENO FELIU, "La transposición de de las Directivas de contratación pública en España y el efecto directo por vencimiento del plazo de incorporación. Consecuencias prácticas", Revista Gallega de Administración Pública, núm. 52, 2016, págs. 265-317. 
principios son respetados. La obligación de transparencia que recae sobre dicha autoridad consiste en garantizar, en beneficio de todo licitador potencial, una publicidad adecuada que permita abrir a la competencia la concesión de servicios y controlar la imparcialidad de los procedimientos de adjudicación (véase en particular la STJUE de 6 de abril de 2006, ANAV apartado 21). Al respecto, es leading case la doctrina fijada por la STJUE de 16 de septiembre de 2013 (Comisión contra Reino de España), aplicable con carácter general a cualquier procedimiento de licitación pública:

«66 El principio de igualdad de trato entre licitadores, que no es más que una expresión específica del principio de igualdad de trato (véase, en este sentido, la sentencia del Tribunal de Justicia de 13 de octubre de 2005, Parking Brixen, C-458/03, Rec. p. I-8585, apartados 46 y 48, y la jurisprudencia allí citada; sentencia del Tribunal General de 12 de marzo de 2008, European Service Network/Comisión, T-332/03, no publicada en la Recopilación, apartado 72) y que pretende favorecer el desarrollo de una competencia sana y efectiva entre las empresas que participan en una licitación, impone que todos los licitadores dispongan de las mismas oportunidades al formular los términos de sus ofertas e implica, por tanto, que éstas estén sometidas a las mismas condiciones para todos los competidores (sentencia del Tribunal de Justicia de 29 de abril de 2004, Comisión/CAS Succhi di Frutta, C-496/99 P, Rec. p. I-3801, apartado 110). De este modo, la entidad adjudicadora está obligada a respetar, en cada fase del procedimiento de licitación, el principio de igualdad de trato de los licitadores (sentencia del Tribunal General de 17 de diciembre de 1998, Embassy Limousines \& Services/Parlamento, T-203/96, Rec. p. II4239 , apartado 85), y éstos deben encontrarse en igualdad de condiciones tanto en el momento en que preparan sus ofertas como en el momento en que éstas se someten a la evaluación de la entidad adjudicadora (véanse, en este sentido, las sentencias del Tribunal de Justicia de 16 de diciembre de 2008, Michaniki, C-213/07, Rec. p. I-9999, apartado 45, y de 17 de febrero de 2011, Comisión/Chipre, C-251/09, no publicada en la Recopilación, apartado 39, y la jurisprudencia allí citada).

67 Por otra parte, el principio de igualdad de trato implica, en particular, una obligación de transparencia para permitir a la entidad adjudicadora garantizar su respeto (véanse las sentencias Lombardini y Mantovani, citada en el apartado 64 supra, apartado 38, y Comisión/Chipre, citada en el apartado 66 supra, apartado 38, y la jurisprudencia allí citada). El principio de transparencia, que constituye el corolario del principio de igualdad de trato, tiene esencialmente por objeto garantizar que no exista riesgo de favoritismo y arbitrariedad por parte de la entidad adjudicadora (sentencias Comisión/CAS Succhi di Frutta, citada en el apartado 66 supra, apartado 111) y controlar la imparcialidad de los procedimientos de adjudicación (véase la sentencia Parking Brixen, citada en el apartado 66 supra, apartado 49, y la jurisprudencia allí citada). Implica que todas las condiciones y modalidades del procedimiento de licitación estén formuladas de forma clara, precisa e inequívoca en el anuncio de licitación o en el pliego de condiciones, con el fin de que, por una parte, todos los licitadores razonablemente informados y normalmente diligentes puedan comprender su alcance exacto e interpretarlos de la misma forma y, por otra parte, la entidad adjudicadora pueda comprobar que efectivamente las ofertas presentadas por los licitadores responden a los criterios aplicables al contrato de que se trata (sentencia Comisión/CAS Succhi di Frutta, citada en el apartado 66 supra, apartado 111). Por último, los principios de igualdad de trato y de transparencia constituyen la base de las Directivas referentes a los procedimientos de adjudicación de contratos públicos. En el deber que incumbe a las entidades adjudicadoras de garantizar la observancia de dichos principios reside la propia esencia de estas Directivas (véase la sentencia Michaniki, citada en el apartado 66 supra, apartado 45, y la jurisprudencia allí citada)».

Se trata, en definitiva, de prevenir la arbitrariedad de la decisión (STJUE de 2 de junio de 2016, Pippo Pizzo ${ }^{13}$.

13 STJUE de 16 de julio de 2014, Asunto T-48/12, Euroscript - Polska Sp. z o.o, que tiene por objeto un recurso de anulación de la decisión del Parlamento de 9 de diciembre de 2011, por la que se modifica la decisión de 18 de octubre de 2011 de clasificar a la demandante en primera posición en la lista de licitadores seleccionados y de adjudicarle el contrato principal en el marco del procedimiento de licitación PL/2011/EU, relativo a la prestación de servicios de traducción al polaco (DO 2011/S 56-090361), y, con carácter subsidiario, una pretensión de anulación de esta licitación. En esta sentencia, que anula una adjudicación de un contrato de servicios 
Por otra parte, la contratación pública debe ser regulada desde la óptica de consecución efectiva y eficiente de la prestación demandada. Esto exige atender con especial interés la fase de ejecución del contrato, que debe ser comprendido desde esta perspectiva del fin derivado de concreta prestación que se demanda. Aquí radica el cumplimiento de los fines públicos que debe prestar la Administración Pública. Por ello, la normativa de los contratos debe tener una «visión completa» de todas las fases del contrato. Y las nuevas Directivas fijan ahora su atención en esta cuestión, regulando la modificación del contrato, la subcontratación o la resolución y fijando que sus principios despliegan efectos en todas las fases del contrato (artículo 18 de la Directiva 2014/24).

Por último, conviene recordar que la contratación pública -y su fundamento- ha cambiado de forma muy notable en los últimos años. De una visión burocrática de la compra pública, diseñada desde una perspectiva hacendística y con escasa prospectiva se ha evolucionado hacia la idea la contratación pública como «herramienta jurídica al servicio de los poderes públicos para el cumplimiento efectivo de sus fines o sus políticas públicas ${ }^{14}$. Esto significa que la contratación pública puede $-y$ debe, insistimos- ser una técnica que permitiera conseguir objetivos sociales, ambientales o de investigación, en la convicción de que los mismos comportan una adecuada comprensión de cómo deben canalizarse los fondos públicos. Se impone, pues, una visión estratégica de la contratación pública alejada de la rígida arquitectura del contrato administrativo y de planteamientos excesivamente burocráticos o formales. El principio de eficiencia, inherente a la contratación pública, no puede ser interpretado desde modelos exclusivamente economicistas, sino que debe velarse por el adecuado estándar de calidad en la prestación del servicio ${ }^{15}$. Es decir, el principio de eficiencia se debe articular atendiendo a objetivos sociales, ambientales o de investigación, en la convicción de que los mismos comportan una adecuada comprensión de cómo deben canalizarse los fondos públicos ${ }^{16}$.

\section{LAS PRINCIPALES NOVEDADES DE LA LEY 9/2017, DE CONTRATOS DEL SECTOR PÚBLICO: UNA VISION «RÁPIDA»}

El texto aprobado (con un título excesivamente extenso al citar a las Directivas que se transponen), que toma como punto de partida el vigente TRLCSP de 2011 (como consecuencia de esta decisión hay un «arrastre» de preceptos de la Ley derogada), «renuncia», tanto formal como materialmente, a la idea de un «Código de Contratos Públicos», con partes diferenciadas en función del objeto: contratos públicos, concesiones, contratos excluidos ${ }^{17}$. Se trata de un texto extenso y prolijo -son 347 artículos y 53 Disposiciones Adicionales (muchas de estas Disposiciones, en adecuada técnica normativa, deberían formar parte del articulado) y 16 Disposiciones Finales-. Y en ciertas ocasiones tiene un marcado carácter reglamentario que puede complicar la aplicación.

del Parlamento europeo por reevaluar la propuesta de la que resulto adjudicataria, recuerda que: "El principio de transparencia implica la obligación del órgano de contratación de hacer pública toda la información precisa referente al desarrollo de todo el procedimiento. Los objetivos de publicidad que dicho órgano de contratación debe respetar en el marco de la obligación de transparencia son, por un lado, garantizar que todos los licitadores dispongan de las mismas oportunidades y, por otro lado, proteger las legítimas expectativas de los licitadores seleccionados (véase, en este sentido, la sentencia del Tribunal de 28 de enero de 2009, Centro Studi Manieri/Consejo, T-125/06, Rec. p. II-69, apartados 86 a 89)." Por ello, al reevaluar una sola de las ofertas presentadas, y no todas las que habían sido presentadas, lo que ocasionó un trato desigual de la oferta de uno de los licitadores, en violación del principio de igualdad de trato.

14 Me remito a mi trabajo "Compra pública estratégica", en libro colectivo Contratación pública estratégica, coord. por J. PERNAS GARCÍA, Aranzadi, 2013, Cizur Menor, págs. 45-80. Este carácter instrumental de la contratación pública es expresamente reconocido en el Informe 6/2014, de 1 de octubre, de la Junta Consultiva de Contratación Administrativa de la Comunidad Autónoma de Aragón sobre Incorporación en los Pliegos de los contratos de una entidad local de determinadas cláusulas sociales, y consecuencias de su eventual incumplimiento y en el Informe 1/2014 de la Junta Consultiva de Contratación Administrativa de Canarias, sobre calificación de contratos típicos y la libertad de pactos.

15 Sobre el significado de la eficiencia -y su no vinculación a una idea economicista de menor precio- me remito a mi estudio "Reglas básicas para mejorar la eficiencia y la transparencia en la contratación pública", número monográfico de la revista Presupuesto y Gasto Público sobre Calidad institucional, transparencia y buen gobierno, núm. 82, 2016, págs. 137-158. También. T. MEDINA ARNAIZ, "Más allá del precio: las compras públicas con criterios de responsabilidad", Papeles de relaciones ecosociales y cambio global, núm. 121, 2013, págs. 87-97 y M. VAQUER CABALLERÍA, "El criterio de la eficiencia en el Derecho administrativo", Revista de Administración Pública, 186, 2011, pág. 91 y ss.

16 J. PONCE, Deber de buena administración y derecho al procedimiento administrativo debido. Las bases constitucionales del procedimiento administrativo y del ejercicio de la discrecionalidad, Lex Nova, Valladolid pág. 479.

17 Así lo propuse en mi trabajo "La necesidad de un Código de Contratos Públicos en España. La contratación pública y las PYMES como estrategia de reactivación económica", en libro colectivo Observatorio de los Contratos Públicos 2011, Civitas, Cizur Menor, 2012, págs. 25-84. 
Es cierto que puede parecer un texto «continuista» o, en palabras de S. DEL SAZ, en relación a la Ley anterior de 2007, «un mismo traje con distintas rayas» ${ }^{18}$. Sin embargo, existen notables diferencias, principalmente porque, tras el debate parlamentario, se han dado importantes pasos para intentar solucionar problemas estructurales de transparencia y de prevención de la corrupción, en especial derivados de la dualidad de regímenes jurídicos en función de la consideración o no de Administración pública, o de debilidad del control, lo que ponía en cuestión el objetivo inicial de impulsar una diferente «gestión práctica» de la contratación pública ${ }^{19}$. Y pretende, además, un cumplimiento de las exigencias europeas, así como una reorientación de la contratación pública desde la perspectiva de estrategia para implementar políticas públicas ${ }^{20}$.

La sistemática formal no resulta innovadora, pues la opción adoptada es «respetar en lo posibles» la estructura del TRLCSP de 2011 (por eso se prevé una Ley de Contratación en sectores especiales). El articulado de esta Ley se ha estructurado en un Título preliminar dedicado a recoger las disposiciones generales en esta materia y cuatro Libros sucesivos, relativos a la configuración general de la contratación del sector público y los elementos estructurales de los contratos (Libro I), la preparación de los contratos administrativos, la selección del contratista y la adjudicación de estos contratos, así como los efectos, cumplimiento y extinción de estos contratos (Libro II), los contratos de otros entes del sector público (Libro III), y, por último, la organización administrativa para la gestión de la contratación (Libro IV).

Sin embargo, desde el contenido, el texto final es distinto del presentado para su tramitación en las Cortes Generales. Son muchas las novedades y ajustes técnicos efectuados ${ }^{21}$. Enumeraremos alguna de las principales:

1. Se incorpora el principio de integridad con la idea de poner de relieve que la voluntad del legislador es laminar al máximo cualquier conducta corrupta o clientelar ${ }^{22}$. El objetivo de integridad reconocido en la Convención de las Naciones Unidas contra la Corrupción- forma parte del derecho a una buena administración que se garantiza en el artículo 41 de la Carta de los derechos fundamentales de la Unión Europea (incorporada ya al ordenamiento español en virtud de la Ley Orgánica 1/2008, de 31 de julio). Y por integridad habrá que entender «el uso de los fondos, los recursos, los activos y las autorizaciones es conforme a los objetivos oficiales inicialmente establecidos, y a que de dicho uso se informa adecuadamente, que es conforme al interés público y que está debidamente armonizado con los principios generales del buen gobierno» (Recomendación del Consejo OCDE sobre contratación pública [C (2015)2]).

El artículo 1 LCSP incluye la referencia a este principio (aunque pasa un tanto desapercibido, lo que aconsejaría una redacción del artículo 1 distinta y «más didáctica»). No es una mera cuestión formal, pues amén del efecto didáctico de su inclusión, se refuerza la idea de que la integridad (la honradez), no es un

18 S. DEL SAZ, "La nueva Ley de Contratos del Sector Público ¿un nuevo traje con las mismas rayas?", RAP, núm.174, 2007.

19 Interesa recordar que algunos de los compromisos del Pacto PP-CIUDADANOS para la investidura de Mariano Rajoy como Presidente del Gobierno, de 28 de agosto de 2016 «150 compromisos para mejorar España» iban en esta línea, abogando por reforzar la competencia y la transparencia en la contratación pública. La medida 109 en concreto recoge lo siguiente: «Impulsar, de forma inmediata, una reforma de la Ley de Contratos del Sector Público que incorpore las las Directivas UE 2014/2023 (LA LEY 4612/2014), 2014/2024 y 2014/con el objetivo de incrementar los controles y cerrar cualquier espacio a irregularidades en las fases de preparación, adjudicación y ejecución. En especial, se limitarán los supuestos de modificación y fraccionamiento de los contratos, sin perjuicio del establecimiento de lotes para favorecer el acceso de las PYMES a la contratación pública, de acuerdo con las mencionadas directivas; así como los del procedimiento negociado sin publicidad. Se reforzará la independencia de los órganos técnicos y profesionales que intervienen en el procedimiento. con el objetivo de incrementar los controles y cerrar cualquier espacio a irregularidades en las fases de preparación, adjudicación y ejecución. En especial, se limitarán los supuestos de modificación y fraccionamiento de los contratos, sin perjuicio del establecimiento de lotes para favorecer el acceso de las PYMES a la contratación pública, de acuerdo con las mencionadas directivas; así como los del procedimiento negociado sin publicidad. Se reforzará la independencia de los órganos técnicos y profesionales que intervienen en el procedimiento».

${ }_{20} \mathrm{El}$ anteproyecto de Ley incluía las referencia expresas a los preceptos de las Directivas que se transponen en cada artículo de la Ley, lo que puede ayudar a una mejor interpretación de la nueva regulación y, en consecuencia, de mayor seguridad jurídica y predictibilidad en un sector de tanta trascendencia económica y social.

21 Algunos de ellos, y los principales cambios, fueron ya sugeridos desde el Observatorio de la contración pública. En especial, resulta de interés el documento «Propuesta de modificaciones y mejora al Proyecto de Ley de Contratos del Sector Público, por el que se transponen al ordenamiento jurídico español las Directivas del Parlamento Europeo y del Consejo, 2014/23/UE y 2014/24/UE, de 26 de febrero de 2014 (Publicado en el Boletín Oficial de las Cortes Generales, Congreso de los Diputados 2 de diciembre de 2016)», publicado en www.obcp.es.

22 Vid. A. CERRILLO I MARTíNEZ, El principio de integridad en la contratación pública: mecanismos para la prevención de los conflictos de interes y la lucha contra la corrupción, Aranzadi, Cizur Menor, 2014. La OCDE, en 2012 (Progress Made in Implementing the OECD. Recommendation on Enhancing Integrity in Public Procurement. París) ha propuesto un conjunto de normas y reglas de integridad así como instrumentos para su análisis y evaluación. Asimismo, ha impulsado diversos procesos de evaluación de varios países para ayudarles a adoptar buenas prácticas e implementar los principios de integridad. 
simple principio ético, sino que tiene efectos jurídicos ${ }^{23}$. Y se adoptan medidas adecuadas a tal fin (aunque no se extiende la aplicación de la norma a partidos políticos y sindicatos y organizaciones profesionales cuando hay financiación pública mayoritaria, como era la opción inicial), con la intención de eliminar (o, al menos reconducir) prácticas que permitían la opacidad.

2. Se refuerza la «visión estratégica de la contratación pública». El artículo $1.3 \mathrm{LCSP}$ supone una clara «innovación» sobre la comprensión práctica de la contratación pública, renunciando a una filosofía burocrática formal y excesivamente economicista para incorporar, de forma preceptiva, la visión estratégica de la contratación pública, incluyendo referencias expresas al valor social y ambiental y la protección de las PYMES. Se abandona así una visión presupuestaria de la contratación pública, que se reorienta a una perspectiva instrumental de implementación de políticas públicas ${ }^{24}$. En especial, se refuerza la posición de los trabajadores en los contratos, estableciendo obligaciones esenciales relativas a la calidad de las condiciones de empleo y de retribución, cuyo incumplimiento puede justificar la resolución del contrato. Y se elimina la posibilidad de «dumping» social mediante precarización de condiciones laborales al establecer la obligación de respetar los convenios sectoriales.

Como complemento a esta visión estratégica de la contratación pública destaca también la previsión respecto a las especialidades de contratación pública en los servicios sanitarios, sociales y educativos dirigidos a las personas, lo que facilita una mejor respuesta jurídica a prestaciones alejadas a la lógica del mercado. Esto significa que un contrato de prestaciones personales de carácter sanitario o social, podría estar excepcionado de las reglas de concurrencia propias de un contrato típico de servicios o productos, dado el marcado carácter estratégico, desde la perspectiva de correcta prestación, del mismo ${ }^{25}$. Se habilita que pueda existir un régimen no contractual para la prestación de estos servicios, así como que se diseñe un régimen singular de contratación ${ }^{26}$.

3. En relación al ámbito subjetivo de aplicación, la principal novedad es que frente a la opción del texto que se remitió a las Cortes Generales de diferenciar el régimen jurídico de los contratos no armonizados en función de su consideración o no de Administración pública (se mantenía así las instrucciones de los entes no Administración pública para los contratos no armonizados ${ }^{27}$, se decide la uniformidad de régimen jurídico, siendo indiferente el carácter o no de Administración pública del poder adjudicador para la aplicación de las reglas de contratación pública en los contratos de importe no a armonizado. Desaparece, pues la posibilidad de regulación mediante Instrucciones internas propias en los procedimientos de importe no armonizado (estas solo quedan para entes del sector público que no sean poder adjudicador -artículo 321 LCSP- o los partidos políticos, sindicatos y organizaciones empresariales -ex artículo 3 LCSP-) ${ }^{28}$.

Se pone fin a una «deslegalización procedimental» que, como se ha venido advirtiendo desde hace tiempo, ha resultado claramente distorsionadora, pues ha permitido la proliferación de distintos y variados procedimientos (distintos plazos, distinta documentación, etc.) que se han convertido en una barrera de entrada para los operadores económicos, a la vez que introducía innecesarias dosis de inseguridad jurídica que favorecían una fragmentación del mercado, la cual, a su vez, favorecía la aparición de prácticas de naturaleza clientelar, que impedían el efectivo funcionamiento -por inadecuada concurrencia- de las econo-

${ }^{23}$ Vid. J. M. GIMENO FELIU, "La reforma comunitaria en materia de contratos públicos y su incidencia en la legislación española. Una visión desde la perspectiva de la integridad", en libro colectivo Las Directivas de Contratación Pública, número monográfico especial Observatorio de los Contratos Públicos 2014, Aranzadi, Cizur Menor, 2015, págs. 37-105.

${ }^{24}$ Se avanza, pues, en la cultura de la contratación socialmente responsable. Cuestión en la que ya se había venido trabajando desde el Foro de contratación socialmente responsable (http://www.conr.es)

${ }^{25}$ Esta opción ha sido «validada» por las Sentencias TJUE de 11 de diciembre de 2014, CroceRossa Italiana y otros (asunto C-113/13) y de 28 de enero de 2016, CASTA y otros, Asunto C-50/14, que reconocen incluso la posibilidad de adjudicación directa. Opción adoptada, por ejemplo, en Aragón por la Ley 11/2016, de 15 de diciembre, de acción concertada para la prestación a las personas de servicios de carácter social y sanitario y por Valencia Ley 7/2017, de 30 de marzo, sobre acción concertada para la prestación de servicios a las personas en el ámbito sanitario).

${ }^{26}$ Me remito a mi trabajo "Servicios de salud y reservas de participación ¿una nueva oportunidad para la mejora del SNS? (Análisis de los artículos 74 a 77 de la nueva Directiva 2014/24/UE sobre contratación pública)", Revista Derecho y Salud, vol. 26, núm. 2 de 2015, págs. 65-85.

${ }_{27}$ No es esa la opción del Proyecto de Ley de Contratos Públicos de Navarra (tramitación iniciada Orden Foral 22/2015, de 29 de enero, de la Consejera de Economía, Hacienda, Industria y Empleo y actualmente en proceso de participación), que ha uniformizado las reglas de la contratación pública en todas las fases con independencia de la naturaleza como Administración pública, o no, del poder adjudicador.

${ }_{28}$ No es que desaparezcan las instrucciones internas, sino que estas tendrán una función «ad intra» para regular los aspectos organizativos de la contratación. Se trata, en definitiva, de prever los aspectos relativos al expediente o pliegos de la licitación, pero no para alterar el modelo procedimental, que se caracteriza ahora por la uniformidad tanto en lo relativo a criterios de solvencia, procedimientos de adjudicación, criterios de adjudicación y condiciones de ejecución y modificación. 
mías de escala. No hay nada más contrario a la efectividad del principio de transparencia que la dispersión normativa y el «caos» regulatorio de los distintos procedimientos de licitación ${ }^{29}$. De ahí que se pueda considerar esta uniformidad jurídica en las reglas procedimentales como la principal novedad del nuevo texto de contratos públicos ${ }^{30}$. Esta uniformidad no se ha extendido, sin embargo (a diferencia del Proyecto de Ley de Contratos Públicos de Navarra), al régimen jurídico de los contratos, cuando la causa de interés público que justifica un régimen exorbitante se encuentra en todos ellos, al margen de la naturaleza, pública o privada, del ente contratante.

En relación al ámbito subjetivo de aplicación, la nueva Ley intenta aclarar el concepto poder adjudicador y las categorías de Administración pública/no administración pública: párrafo 1 se mantiene para definir que es sector público. El párrafo 3 indica quien es poder adjudicador y su utiliza el sistema de lista, aunque no se precisa el concepto conforme a los criterios ya fijados por el TJUE. El párrafo 2 se indica quien tiene consideración de Administración Pública. Se suprime la mención a que las Entidades Públicas Empresariales (EPE) no se comportan como Administración Pública y se acuerda que solo las entidades de derecho público que sean efectivamente de mercado serán no Administración Pública a efecto de esta Ley (opción ya implantada tras la entrada en vigor de la Ley 40/2015, lo que obliga a «revisar» la categorización como EPE y el régimen jurídico que le resulta de aplicación) ${ }^{31}$. Además, en todo caso, cualquier ente considerado como medio propio (en tanto cumpla las exigencias auto-organizativas que justifica su creación), serán, en todo caso, poder adjudicador, sin que sea posible, mediante la «forma jurídica» huir de las reglas de la contratación pública ${ }^{32}$.

29 Sobre esta patología vengo insistiendo desde mi trabajo "El nuevo ámbito subjetivo de aplicación de la Ley de Contratos del Sector Público: luces y sombras", RAP, núm.176, 2008, págs. 9-54 en la que he insistido en el estudio "La corrupción en la contratación pública...", ob. cit., págs. 258-262. Igualmente, B. NOGUERA DE LA MUELA, "La transparencia en la contratación pública: entre las reglas europeas y el ordenamiento jurídico español”, en libro homenaje al profesor L. Cosculluela, Régimen jurídico básico de las Administraciones Públicas, lustel, Madrid 2015, págs. 948-950. Afirmación que entiendo queda avalada por la propia realidad por cuanto el número de entes existentes considerados poderes adjudicadores no administración pública (más de diez mil), per se, conlleva a tal dispersión de reglas distintas (de difícil localización, por lo demás) que hace inviable que los licitadores puedan conocer los distintos procedimientos, lo que conduce a un mercado "cerrado" claramente ineficiente y alejado del objetivo de efectiva transparencia.

30 No puede olvidarse que en el «océano proceloso» de entes diversos la confusión jurídica derivada de la multiplicidad de Instrucciones internas, ha permitido, quizá sin pretenderlo, la proliferación de redes clientelares y de prácticas que han podido facilitar la captación de financiación ilegal que se ha derivado, directa o indirectamente a las organizaciones políticas.

31 Ver J. M. GIMENO FELIU, "La incidencia de la nueva Ley de Régimen Jurídico del Sector Público en el régimen de contratación de ciertos poderes adjudicadores y de la Ley de Procedimiento Administrativo Común en la posibilidad de control”, Revista Contratación Administrativa Práctica, núm. 147, 2017, págs. 6-9. En esta línea se ha manifestado el Informe de la Junta Consultiva de Contratación Administrativa de Aragón 20/2016, donde recuerda que «El cambio operado en la Ley 40/2015, que aunque no es básica en la definición del concepto de entidad pública empresarial, debe ser considerado a efectos de interpretar el art. 3.2.e) TRLCSP (precepto que sí es básico) que alude a las "Entidades Públicas Empresariales estatales y sus análogas autonómicas y locales", obliga a revisar la conclusión alcanzada en la antecitada Circular. Así, para afirmar ahora que las Entidades Públicas Empresariales estatales y sus análogas autonómicas y locales no tendrán la consideración de Administración pública a efectos de contratación debe atenderse a la circunstancia de que se financien "mayoritariamente con ingresos de mercado" como dato relevante para determinar su régimen de contratación. Si la financiación de una entidad autonómica no procede "mayoritariamente de ingresos de mercado" no cabrá entonces afirmar su naturaleza análoga a las Entidades Públicas Empresariales, y por tanto, su contratación quedará sometida íntegramente a las disposiciones del TRLCSP, sin que resulte admisible que la adjudicación de sus contratos no sujetos a regulación armonizada se regule en unas instrucciones internas de contratación (...)Y, para delimitar cuándo se entenderá que se financian mayoritariamente con ingresos de mercado, deberá estarse a su consideración, o no, de productor de mercado de conformidad con el Sistema Europeo de Cuentas (SEC 2010), regulado en el Reglamento (UE) núm. 549/2013 del Parlamento Europeo y del Consejo, de 21 de mayo de 2013 , relativo al Sistema Europeo de Cuentas Nacionales y Regionales de la Unión Europea, de directa aplicación».

32 Así se ha advertido, para la gestión de los mercados municipales a través de empresas públicas configuradas como medios propios (el caso MERCASA), en la Resolución 23/2015 del Órgano de Recursos Contractuales del País Vasco, el Acuerdo del Tribunal Administrativo de Contratos Públicos de Aragón 104/2015 y la Resolución 125/2016 Tribunal de Contratos Públicos de Madrid. Doctrina extensible a cualquier medio propio por exigencia del Derecho europeo, tal y como se argumenta en las las Conclusiones del Abogado General M. CAMPOS SÁNCHEZ-BORDONA presentadas el 27 de abril de 2017 (asunto C567/15) UAB «LitSpecMet», se analizan los requisitos para la consideración de una entidad como poder adjudicador y, en especial, la configuración que al respecto debe hacerse de una entidad que sea calificada como medio propio. Y su conclusión es que «una sociedad cuya vinculación material y funcional con un poder adjudicador justifica la excepción in house para sus operaciones internas, está sometida a aquellas Directivas cuando contrata con terceros obras, suministros o servicios, a fin de cumplir la encomienda que le hubiera confiado el poder adjudicador». Criterio confirmado en la STJUE de de 5 de octubre de 2017, UAB LitSpecMet, donde afirma que «una sociedad que, por una parte, pertenece en su totalidad a un poder adjudicador cuya actividad consiste en satisfacer necesidades de interés general y que, por otra parte, Ileva a cabo tanto operaciones para dicho poder adjudicador como operaciones en el mercado competitivo, debe calificarse de "organismo de Derecho público" en el sentido de esta disposición, siempre que las actividades de dicha sociedad sean necesarias para que ese poder adjudicador pueda ejercer su actividad y que, para satisfacer necesidades de interés general, la referida sociedad se guíe por consideraciones que no sean económicas, extremo que ha de verificar el órgano jurisdiccional remitente. Carece de pertinencia a este 
Los órganos constitucionales y equivalente autonómicos, a los efectos de esta Ley, tienen consideración de Administración pública, tal y como se previene en la Disposición Adicional 44.

Sin embargo, y frente a la opción contenida en el proyecto en remisión a las Cortes Generales, se excluye a partidos políticos y sindicatos y organizaciones empresariales si hay financiación pública mayoritaria, limitando las exigencias a la aplicación de unas Instrucciones. Esta decisión, que es discutible técnicamente, no parece acertada en un contexto de regeneración democrática que debe ser liderada por las organizaciones políticas y cuestiona su propia legitimidad ${ }^{33}$. Por ello sería oportuno revisar esta decisión y «volver a la opción inicial» e incluirlos en el concepto de poder adjudicador ${ }^{34}$.

4. En negocios excluidos se mejora la sistemática, con varios preceptos distintos que contengan una materia idéntica y un último «cajón de sastre». En cuestión de convenios (se introduce el término de "cooperación»), se sustituye «naturaleza» por contenido y causa (se pretende evitar fraudes y favorecer control y que bajo subterfugios formales se esconda una relación que es un contrato público). La letra d) se cambia la mención de Administración Pública por la de poder adjudicador.

Asimismo, se da sustantividad a compra pre-comercial, si bien aquí convendría insistir en la diferenciación de adquisición de servicios de I+D en régimen de ayudas públicas (negocio excluidos), de la compra pública pre-comercial en la que debe existir un reparto de beneficios y riesgos y, obviamente, un procedimiento público. La compra pública pre-comercial, como procedimiento de licitación, permite la financiación europea, pero no así si se configura como ayuda pública. Este punto me parece muy relevante y de especial atención para no perjudicar la estrategia de impulso de innovación en España (conviene recordar que se introduce un nuevo procedimiento para la compra de innovación: la asociación para la innovación).

Los contratos celebrados en el ámbito de la Defensa y Seguridad, seguirán rigiéndose por su correspondiente Ley específica (Ley 24/2011, de 1 de agosto, de contratos del sector público en los ámbitos de la defensa y de la seguridad), en los supuestos en ella determinados. Se delimita en el texto, así mismo, la aplicabilidad de la presente Ley o de la ley específica, según los distintos supuestos posibles en el caso de contratos referidos a los sectores del agua, la energía, los transportes y los servicios postales.

5. Se regula la cooperación vertical y horizontal (los medios propios y convenios). Se opta por utilizar las categorías y conceptos comunitarios, con el fin de favorecer la predictibilidad. Así, no se habla de encomiendas sino de encargos ${ }^{35}$. Encargos que deben ser objeto de publicidad con el fin de garantizar, mediante el control, la idoneidad de cada encargo. Los entes que tengan consideración de medios propios deben contar con los medios idóneos ${ }^{36}$. En todo caso, cien por cien capital públicos. Son necesarios, además, otros requisitos: que la empresa que tenga el carácter de «medio propio»; disponga de medios suficientes para cumplir el encargo que se le haga; que haya recabado autorización del poder adjudicador del que dependa; que no tenga participación de una empresa privada y que no pueda realizar libremente en el mercado más de un $20 \%$ de su actividad. Obviamente, cualquier ente considerado como medio propio, es, en todo caso, poder adjudicador. Así se ha advertido, para la gestión de los mercados municipales a través de empresas públicas configuradas como medios propios, en la Resolución 23/2015 del Órgano de Recursos Contractuales del País Vasco, el Acuerdo del Tribu-

respecto el hecho de que el valor de las operaciones internas pueda representar, en un futuro, menos del $90 \%$ del volumen de negocios global de la sociedad o una parte no esencial de éste».

33 Se ajustan, igualmente, cierta previsiones relativas a la Administración local, tanto en materia de organización, cuantías de contrato menor en función de población y de elementos de control. Sobre la incidencia de la Directiva 2014/24 en la Administración local resulta de especial interés el trabajo de M. A. BERNAL BLAY, "La contratación de las Entidades Locales en el nuevo paquete legislativo europeo sobre contratación pública", REALA, núm. 2, nueva época, 2014.

34 Me remito a mi trabajo "Medidas de prevención de corrupción y refuerzo de la transparencia en la contratación pública". REA$L A$, núm. 7, 2017. Esta «publificación» de la actividad contractual es necesaria tanto para conocer las necesidades de obras, servicios y suministros de los partidos políticos, así como para la selección de los proveedores en régimen de concurrencia, lo que dificultaría actuaciones irregulares en la financiación indirecta de los partidos políticos. Vid. mi trabajo "Medidas de prevención de corrupción y refuerzo de la transparencia en relación con la financiación de partidos políticos", libro Observatorio de los Contratos Públicos 2016, Aranzadi, Cizur Menor, 2017, págs. 27-44.

35 Criterio ya aplicado por el Tribunal de Contratos Públicos de Aragón en su acuerdo 75/2017, de 4 de julio, donde se aplica la jurisprudencia del TJUE sobre cooperación vertical y cooperación horizontal, para poder decidir la anulación de una «remuncipalización» incorrectamente instrumentada bajo la justificación de encomienda de gestión a medios propios.

36 Criterio defendido en el Informe 65/07, de 29 de enero de 2009 de la Junta Consultiva de Contratación Administrativa del Estado -«Consideración de medio propio de un Ayuntamiento y de sus organismos autónomos de una sociedad municipal y procedimiento de encomienda de gestión»-, añade a los requisitos mencionados el de la idoneidad del ente para recibir y prestar el encargo afirmando: «Habrá que añadir un último requisito, como es la idoneidad para ejecutar la encomienda de gestión y en tal sentido debe disponer de personal y medios materiales y técnicos necesarios para ejecutar la encomienda». 
nal Administrativo de Contratos Públicos de Aragón 104/2015 y la Resolución 125/2016 Tribunal de Contratos Públicos de Madrid. Sin embargo, la posibilidad de contratar hasta un 50 por ciento de las prestaciones resulta claramente excesiva y puede no corregir un uso indebido de esta técnica (como ya ha denunciado el Tribunal de Cuentas) ${ }^{37}$. Resultaría más lógico limitar esta opción al 20 por ciento de la cuantía del encargo, y sin afectar al contenido esencial de la prestación.

La Disposición Adicional 24 contiene una regulación extensa del grupo empresarial TRAGSA, al que se permite tener la consideración de medio propio incluso de Diputaciones y Cabildos (siempre que se cumplan los requisitos legales -interpretados de conformidad a la jurisprudencia del TJUE-, lo que no parece sencillo).

6. En la tipología de contratos hay ajuste de definiciones de obras y servicios y se opta por el concepto funcional de obras: que exista influencia en la decisión final (STJUE 30 octubre 2009, Comisión/ Alemania) y de concesión de obras y de concesión de servicios. Desaparece, por ello, el tipo contractual de servicios públicos ${ }^{38}$. Lo que no impide un régimen jurídico «más intenso» en prestaciones de servicio público (lo que explica el régimen especial de servicios a las personas que contiene la Ley en el artículo 312, que recoge el «régimen de servicio público» en estas actividades esenciales) ${ }^{39}$.

El artículo 29 LCSP regula los plazos de los contratos y opta por qué plazo el de contratos de servicios y concesiones sea común a todo poder adjudicador con excepciones justificadas (como el retorno de las inversiones, complejidad del servicio, etc. ${ }^{40}$. El plazo ordinario de duración de los contratos de servicios y concesión de servicios es de 5 años (porque es el que referencia la Directiva concesiones). Desaparece, el tipo de contrato de colaboración público-privada (pero se mantiene, mediante la previsión de la Disposición Adicional 22, la posibilidad de sociedad de economía mixta en tanto fórmula de CPPI tanto para obras como servicios ${ }^{41}$ ). Esta decisión está motivada en la experiencia práctica y se pretende evitar confusiones o incorrecto uso. En todo caso, la opción de realizar CPP (desde de la perspectiva de SEC 2010) se encuentra en la regulación de concesiones. Se incorpora, por lo demás, una definición contrato servicios conforme al Derecho de la Unión Europea y la interpretación dada por el TJUE. Así, se incluye contrato concesión de servicios, que se caracteriza por la transferencia de un riesgo operacional. Ya no hay contrato de gestión de servicios públicos y se eliminan formalmente las figuras del concierto y de la gestión interesada (aunque la una se mantiene como contrato de servicios y la otra se engloba en el nuevo concepto de concesión). Interesa recordar que en la tipificación de una prestación como contrato de servicios o como contrato de concesión se exige, por exigencia de la jurisprudencia europea ${ }^{42}$, una interpretación funcional, corrigiendo prácticas que eludan la aplicación de las Directivas (STJUE de 29 de octubre de 2009 (Comisión/Alemania) ${ }^{43}$.

37 Vid, por todos, el reciente Informe del Tribunal de Cuentas núm. 1197/2016, de 22 de diciembre, de fiscalización sobre la utilización de la encomienda de gestión, regulada en la legislación de contratación pública aplicable, por las entidades del sector público autonómico español durante el ejercicio 2013.

38 Frente a la opinión en este aspecto del Consejo de Estado. La tesis a favor de la supervivencia del contrato de gestión de servicios públicos ha sido defendida y argumentada por J. L. MARTíNEZ ALONSO en su trabajo "Modificación de la Ley de Contratos del Sector Público y gestión de servicios públicos locales: propuestas y alternativas". Revista General de Derecho Administrativo, núm. 40, octubre 2015. También F. HERNÁNDEZ GONZÁLEZ propone reajustar la categoría del contrato de gestión de servicios públicos y mantener el modelo de conciertos. "La controvertida supresión del contrato de gestión de servicios públicos", En El Cronista del Estado Social y Democrático de Derecho, núm. 60, 2016, págs. 50-57.

39 No comparto la critica a este opción de transposición formulada por el profesor J. L. MARTíNEZ LÓPEZ-MUÑIZ en su estudio "Sentido y alcance de la transposición de las directivas de la Unión Europea (análisis particular en materia de contratación pública)", $R A P$, núm. 202, 2017, págs. 13-41. El modelo propuesto preserva las notas de garantía, continuidad y calidad de los servicios públicos, y la homogeneidad de tipo, en un contexto globalizado de la contratación pública, favorece una mejor interpretación y aplicación de los principios europeos de la contratación pública.

40 Sobre el significado de la nueva regulación europea de la colaboración público-privada me remito al libro Servicios públicos e ideología. El interés general en juego (F. CAAMAÑO, J. M. GIMENO, P. SALA y G. QUINTEROS), ob. cit., págs. 57-83.

41 A favor de esta eliminación de contrato CPP del artículo 11 TRLCSP se puede ver la opinión de M. MAGIDE HERRERO, "Marco legal de la colaboración público-privada; algunas referencias particulares al ámbito de la defensa", en libro colectivo El futuro de la colaboración del sector privado con el sector público, ed. AESMIDE/Fundación Areces, Madrid, 2012, págs. 68-69. Ciertamente, como bien ha sistematizado, en un análisis exhaustivo, son muchas las variables y complejidades de este tipo contractual "específicamente español” y, quizá, por ello convenga su eliminación para uniformizar las categorías y conceptos en un marco normativo europeo. Máxime, como indica M. HERNANDO RYDINGS, en contratos de estas características, que aconsejan la mayor certeza del entramado jurídico y económico. La colaboración público privada. Fórmulas contractuales, Civitas, 2012, págs. 534-541. También M. A. FERNÁNDEZ SCAGLIUSI, "El necesario cambio de configuración del contrato de colaboración entre el sector público y el sector privado ante su escaso empleo en la práctica", REDA, núm. 167, 2014, págs. 293-326.

42 Sentencias del TJUE de 10 de septiembre de 2009, Wasser, 10 de marzo de 2011, Privater Rettungsdienst, y 10 de noviembre de 2011, Norma-A, SIA.

43 Según esta doctrina consolidada, existirá un «contrato de servicios» en el sentido de las Directivas en un contrato mediante el cual un contratante, en virtud de las normas de Derecho público y de las cláusulas contractuales que regulan la prestación de estos 
Se adopta el criterio del riesgo operacional (lo que no implica traspasar todo el riesgo, pero tampoco reconducirlo a la mera idea de riesgo y ventura) como elemento para delimitar concesión de contrato, lo que supone un cambio, pues bastara con que se transfiera el riesgo de suministro de oferta o el riesgo de suministro de demanda para que exista una concesión (criterio aplicable por igual a concesiones de obras o concesiones de servicio) $)^{44}$. Se considerará que el concesionario asume un riesgo operacional cuando no esté garantizado que, en condiciones normales de funcionamiento, vaya a recuperar las inversiones realizadas ni a cubrir los costes que haya contraído para explotar las obras o los servicios que sean objeto de la concesión. La parte de los riesgos transferidos al concesionario supondrá una exposición real a las incertidumbres del mercado que implique que cualquier pérdida potencial estimada en que incurra el concesionario no es meramente nominal o desdeñable "Un riesgo operacional debe derivarse de factores que escapan al control de las partes. Los riesgos vinculados, por ejemplo, a la mala gestión, a los incumplimientos de contrato por parte del operador económico o a situaciones de fuerza mayor, no son determinantes a efectos de la clasificación como concesión, ya que tales riesgos son inherentes a cualquier tipo de contrato, tanto si es un contrato público como si es una concesión. Un riesgo operacional debe entenderse como el riesgo de exposición a las incertidumbres del mercado, que puede consistir en un riesgo de demanda o en un riesgo de suministro, o bien en un riesgo de demanda y suministro. Debe entenderse por "riesgo de demanda" el que se debe a la demanda real de las obras o servicios objeto del contrato. Debe entenderse por "riesgo de oferta" el relativo al suministro de las obras o servicios objeto del contrato, en particular el riesgo de que la prestación de los servicios no se ajuste a la demanda. A efectos de la evaluación del riesgo operacional, puede tomarse en consideración, de manera coherente y uniforme, el valor actual neto de todas las inversiones, costes e ingresos del concesionario". (Considerando 20 de la Directiva de concesiones) ${ }^{45}$.

Es preciso comprobar, por tanto, si el modo de remuneración acordado consiste en el derecho del prestador a explotar un servicio (u obra) e implica que éste asume el riesgo de explotación del servicio (u obra) en cuestión. Si bien este riesgo puede ser ciertamente muy limitado desde el primer momento, la calificación de concesión requiere no obstante que la entidad adjudicadora transfiera al concesionario la totalidad o, al menos, una parte significativa del riesgo que corre ${ }^{46}$. Obviamente, no resulta razonable exigir a la autoridad pública concedente transferir riesgos económicos superiores a las que existe en el sector de acuerdo con la normativa aplicable (sobre los que la entidad adjudicadora carece de margen de decisión) ${ }^{47}$.

servicios, no asume una parte significativa del riesgo que corre el poder adjudicador. Así, por ejemplo, el transporte de pacientes en ambulancias no será un contrato de gestión de servicios públicos sino de servicios, tal y como se advierte en la STJUE de 18 de diciembre de 2007 (Comisión/República Irlanda). Con matices a tal calificación puede verse la STJUE de 29 de abril de 2010 (Comisión/República de Alemania). En esta Sentencia se recuerda que los servicios de transporte sanitario de urgencia o de transporte especial de enfermos, sobre los que versa el presente asunto, se incluyen a la vez en la categoría 2 o 3 del anexo I A de la Directiva $92 / 50$ o del anexo II A de la Directiva 2004/18, y en la categoría 25 del anexo I B de la Directiva 92/50 o del anexo II B de la Directiva 2004/18, de modo que los contratos que tienen por objeto tales servicios están sujetos a la aplicación del artículo 10 de la Directiva $92 / 50$ o del artículo 22 de la Directiva 2004/18 (véase, en este sentido, la sentencia de 24 de septiembre de 1998, Tögel, C-76/97, Rec. p. I-5357, apartado 40). Doctrina aplicada por el Tribunal Administrativo de Contratos Públicos de Aragón en su Acuerdo 52/2013 de 11 de septiembre, que califica como contrato de servicios la prestación de hemodiálisis, por no existir riesgo (criterio confirmado por Acuerdos 55/2013 $737 / 2014$, del TACPA). También por el TACRC, que en su Resolución 134/2013 de fecha 19 de septiembre de 2014 hace suya la distinción entre el riesgo propio de todo contrato y el riesgo específico de los contratos de gestión de servicios públicos que hace el TJUE en la sentencia 348/10 Norma-A y Dekom (en las Resoluciones 154 y 220/2011 declara que la asunción de riesgo por parte del concesionario es lo que caracteriza al contrato como concesión de servicios). Este mismo criterio ha sido compartido por el órgano de recursos contractuales de Cataluña (Resoluciones 24/2013, de 28 de enero, 50/2013, de 25 de marzo y 19 de septiembre de 2013) y Tribunal de Contratación Pública de Madrid (Resolución 48/2014, de 19 de marzo).

44 Existen problemas derivados de SEC 2010: ahora es transferencia de riesgo de demanda, o riesgo de oferta, o de ambo (son, pues, distinto a criterios de SEC 95). Sobre la incidencia del nuevo sistema de cómputo de déficit en SEC 2010 puede consultarse el trabajo de A. B. MACHO PÉREZ y E. MARCO PEÑAS, "El impacto de las colaboraciones público-privadas en los niveles de déficit y deuda pública: análisis de los criterios de EUROSTAT", RAP, núm. 194, 2014, 437-474.

45 Para determinar la existencia, o no, de riesgo operacional, debe tenerse en cuenta los criterios del TJUE sobre este asunto.

46 Como bien ha recordado M. FUERTES, el TJUE ha admitido las peculiaridades que algunas prestaciones tienen, que la regulación puede limitar los riesgos, que la Administración contratante pueda estar atenta a las vicisitudes... para reconocer que no se trata de un contrato de servicio. Así, por ejemplo, en la sentencia que resuelve el conflicto del servicio de abastecimiento de aguas en la comarca de Gotta (de 10 de septiembre de 2009, C-206/08) y en la que resuelve la cuestión prejudicial relativa a los contratos de transporte de asistencia médica y urgencias en Baviera (de 10 de marzo de 2011, C-274/09. "Los riesgos del riesgo de explotación", en libro colectivo Observatorio de los Contratos Públicos 2012, Aranzadi, 2013, pág. 235.

47 Como bien advierte la STJUE de 10 de septiembre de 2009, Eurawasser, apartados 77 y 80 . EI matiz es importante, pues solo así se consigue no desincentivar la iniciativa privada (vid. X. LAZO VITORIA, "EI futuro del mercado concesional en Europa" REVISTA CEFLEGAL. CEF, núm. 154 (noviembre 2013), 154; L. MíGUEZ MACHO), "Fórmulas de colaboración público-privada contractual y 
El plazo concesiones queda vinculado al plazo necesario de retorno de las inversiones (como plazo ordinario, se fija el de cinco años que exige la Directiva de concesiones). Es decir, no hay discrecionalidad en la decisión del plazo concesional de tal manera que los plazos máximos que ofrece la LCSP no son de directa aplicación. El plazo es un elemento esencial, que debe ser ajustado al reparto de riesgos y que no puede favorecer de forma desproporcionada al concesionario por excesiva duración, pues -además de ayuda estatal ilegal conforme a las previsiones del artículo 107 TFUE- puede implicar una retribución indebida (en más) ${ }^{48}$.

La eliminación del tipo de contrato de gestión de servicios públicos no implica una involución desde la perspectiva de la mejor prestación de los servicios de interés general, pues en modo alguno se diluye el «régimen de servicio público», dado que las notas propias de regularidad, continuidad y equidad se pueden incluir tanto en el tipo de contrato de servicios como de concesión de servicios.

Se regula el contrato mixto, conforme a la jurisprudencia del TJUE, atendiendo a regla general de valor estimado de la prestación principal (artículo 13 LCSP). Se aclara que los contratos administrativos/privados son, en esencia, «régimen jurídico» y no, por tanto, tipo de contratos (artículos 24 a 26 LCSP).

En todo caso, conviene insistir en que el debate sobre la forma de prestación de los servicios públicos, en sentido estricto, debe pivotar sobre la esencia de la propia idea y función del servicio público ${ }^{49}$, es decir, la regularidad, continuidad y neutralidad en la prestación, garantizando la mejor calidad del servicio a los ciudadanos. No interesa tanto que sea gestión directa o indirecta como la mejor prestación (también en parámetros de eficiencia) de la actividad ${ }^{50}$. Es decir, debe prevalecer la idea del nivel óptimo de gestión. El alcance sobre las fórmulas de colaboración público privadas y su función en la consecución del interés público, más allá de las personales posiciones ideológicas, exige una respuesta en clave jurídica, que concilie de forma adecuada los distintos principios e intereses en juego, y que preserve, en su decisión final, la esencia del derecho a una buena administración. Hay que evitar el maniqueísmo sobre quien presta mejor el interés general y, para ello, hay que garantizar el equilibrio entre lo público y lo privado y preservar, por supuesto, los principios de seguridad jurídica y de confianza legítima en inversiones de larga duración, que no son contrarios, sino complementarios, con los de control de la prestación y de adecuada regulación de los servicios públicos, de los que nunca podrá abdicar una Administración diligente.

7. Como novedades de la solvencia de los licitadores, conviene advertir como en se aclara como condición de ejecución lo que es la adscripción de medios como complemento necesario a la solvencia que se exige. La clasificación empresarial se mantiene solo en contratos de obras de más de 500000 euros.

Procede destacar la previsión del artículo 75 LCSP, que transpone el artículo 63 de la Directiva 2014/24/ UE, que permite la integración de la solvencia con medios externos a la propia empresa licitadora (lo que

crisis financiera del sector público", en FERNÁNDEZ ACEVEDO, R., y VALCÁRCEL FERNÁNDEZ, P., La contratación pública a debate: presente y futuro, Civitas, Cizur Menor, 2014, págs. 181-185).

${ }_{48}$ Esta es una cuestión en la que la Directiva 2014/23 insiste, de tal manera que se fija un plazo orientativo de cinco años, que solo podrá ser mayor respetando la regla de que "la duración máxima de la concesión no podrá exceder el tiempo que se calcule razonable para que el concesionario recupere las inversiones realizadas para la explotación de las obras o servicios, junto con un rendimiento sobre el capital invertido, teniendo en cuenta las inversiones necesarias para alcanzar los objetivos contractuales específicos" (artículo 18). Este plazo se explica, en el considerando 52 de la Directiva, de la siguiente manera: «La duración de una concesión debe limitarse para evitar el cierre del mercado y la restricción de la competencia. Además, las concesiones de muy larga duración pueden dar lugar al cierre del mercado, obstaculizando así la libre circulación de servicios y la libertad de establecimiento. Ahora bien, tal duración puede estar justificada si resulta indispensable para permitir que el concesionario recupere las inversiones previstas para la ejecución de la concesión y obtenga además un beneficio sobre el capital invertido. Por lo tanto, para las concesiones de duración superior a cinco años la duración ha de estar limitada al período en el que resulte razonablemente previsible que el concesionario pueda recuperar las inversiones realizadas para explotar las obras y servicios, más un beneficio sobre el capital invertido en condiciones normales de explotación, teniendo en cuenta los objetivos contractuales específicos que haya asumido el concesionario a fin de satisfacer exigencias tales como la calidad o el precio para los usuarios. Esta previsión ha de ser válida en el momento de la adjudicación de la concesión. Debe ser posible incluir las inversiones iniciales y posteriores consideradas necesarias para la explotación de la concesión, como gastos de infraestructura, derechos de propiedad intelectual, patentes, equipo, logística, contratación, formación del personal y gastos iniciales. La duración máxima de la concesión debe estar indicada en los documentos relativos a la misma, a menos que la duración constituya un criterio para la adjudicación del contrato. Los poderes y entidades adjudicadores siempre deben poder adjudicar una concesión por un período inferior al necesario para recuperar las inversiones, siempre y cuando la compensación correspondiente no elimine el riesgo operacional».

49 Concepto de servicio público de difícil delimitación conceptual, como ya ha advertido la STC 127/1994, de 5 de mayo, al afirmar que "la idea de servicio público no constituye una noción unívoca y sí un concepto muy debatido por la doctrina jurídica -con detractores y valedores-, sujeto a distintas elaboraciones y utilizado en diversos momentos históricos con finalidades también distintas".

50 El contrato público y la concesión son herramientas para la mejor satisfacción de necesidades de la ciudadanía, por lo que hay que preservar una gestión pública que preserve la idea del necesario equilibrio jurídico entre lo público y lo priado y la seguridad jurídica de las inversiones. Al respecto, in totum, me remito al estudio de J. M. GIMENO, P. SALA y G. QUINTEROS, El interés público y su satisfacción con la colaboración público-privada. Fundamentos, equilibrios y seguridad jurídica, Cámara de Comercio de Barcelona, 2017. 
viene a posibilitar que en fase de solvencia se concrete el nivel de «subcontratación» para la ejecución de un contrato) y que conforman el concepto funcional de operador económico ${ }^{51}$. Este precepto legal permite que, para acreditar y completar su solvencia, los licitadores puedan basarse en la solvencia de otras empresas, independientemente de la naturaleza jurídica de los vínculos que tengan con ellas (en el supuesto de personas jurídicas dominantes de un grupo de sociedades se podrán tener en cuenta las sociedades pertenecientes al grupo, siempre y cuando aquéllas acrediten que tienen efectivamente a su disposición los medios, pertenecientes a dichas sociedades, necesarios para la ejecución de los contratos). Se trata de un derecho de los potenciales licitadores que ni tiene que ser previsto, ni puede ser limitado mediante el pliego de la licitación. Y que no se limita, en modo alguno, a empresas de un mismo grupo empresarial.

Desde la perspectiva de simplificación destaca que se establece la declaración responsable como regla general de acreditación de la solvencia en los procedimientos abiertos. Y se regula el modelo de documento (el DOUE del día 6 de enero de 2016, serie L 3, publica el Reglamento de Ejecución (UE) 2016/7 de la Comisión de 5 de enero de 2016 por el que se establece el formulario normalizado del documento europeo único de contratación). Documento Único Europeo que, en tanto medida de simplificación, tiene por función que los pliegos no incluyan la exigencia de presentar la documentación administrativa en tanto carga para el licitador. Lo que significa, desde una interpretación sistemática, que los pliegos deben prever en contratos armonizados como única forma de acreditación en fase de solvencia de la licitación la necesaria presentación del Documento Único Europeo (resultaría coherente que tal decisión se extienda también a los contratos de importe no armonizado).

Asimismo, se incluye un precepto dedicado a Lucha contra la corrupción y prevención de los conflictos de intereses ${ }^{52}$. Se establece un nuevo modelo prohibición de contratar, que es el mismo para cualquier poder adjudicador, sea o no Administración Pública. Se extiende el régimen de familia (la prohibición se extiende igualmente, en ambos casos, a los cónyuges, personas vinculadas con análoga relación de convivencia afectiva, ascendientes y descendientes, así como a parientes en segundo grado por consanguinidad o afinidad de las personas a que se refieren los párrafos anteriores, cuando se produzca conflicto de intereses) y se ajusta la prohibición al «contrato». Se regula un nuevo sistema y procedimiento de determinación de las prohibiciones de contratar (vinculado a cada contrato), que no incluye la opción de «clemencia» que figura de forma clara y precisa en la Directiva 2014/24 lo que supone una contravención de esta norma europea.

8. Con la nueva LCSP se introduce más transparencia en los procedimientos, con exigencia de justificación y motivación de la necesidad y del procedimiento elegido (artículo 116.4 LCSP). Se exige, además, una detallada información que se debe publicar en los perfiles de contratante. Perfiles de contratante que, como indica el artículo 347 LCSP deberán alojarse de manera obligatoria en la Plataforma de Contratación del Sector Público, gestionándose y difundiéndose exclusivamente a través de la misma. En las páginas web institucionales de estos órganos se incluirá un enlace a su perfil de contratante situado en la Plataforma de Contratación del Sector Público (la publicidad en el Boletín oficial no es ya obligatorio y será gratuito $)^{53}$. Y lo que es más importante, desde la perspectiva de cumplimiento de esta obligación, es

51 Este criterio, aunque la Directiva se encontraba en plazo de transposición, ya ha sido aplicado por la Audiencia Nacional, en su sentencia de 25 de febrero de 2015 (recurso 0000463 /2013) anulando el criterio más formal y restrictivo del Tribunal Administrativo Central de Recursos Contractuales, indicando que los «operadores econoìmicos» pueden alegar la experiencia profesional de otras entidades -en esta liìnea de interpretación amplia tambén cabe citar la SAN 59 de 16 de marzo de 2011 (Rec. $71 / 2010$ ) o la SAN 39 de 4 de noviembre de 2013 (Rec 444/2012)-.

52 Sobre el conflicto de intereses el Acuerdo 108/2016, de 9 de noviembre de 2016 del Tribunal administrativo de Contratos Públicos de Aragón indica que «Del Derecho europeo y de la Directiva 2014/24/UE se deduce, en relación al conflicto de intereses como causa de exclusión que: a) No se requiere que el conflicto sea «real» en cuanto que el interés particular influya de facto en el desempeño de la actividad pública, sino que pueda ser "percibido" como comprometedor de la objetividad, la imparcialidad y la independencia requerida en el procedimiento de contratación; b) No existe una obligación absoluta de los poderes adjudicadores de excluir sistemáticamente a los licitadores en situación de conflicto de intereses, dado que tal exclusión no se justifica en aquellos casos en que puede probarse que tal situación no ha tenido ninguna incidencia en su comportamiento en el marco del procedimiento de licitación, y que no supone un riesgo real de que surjan prácticas que puedan falsear la competencia entre los licitadores; c) La exclusión de un licitador en situación de conflicto de intereses resulta indispensable cuando no se dispone de un remedio más adecuado y menos restrictivo para evitar cualquier vulneración de los principios de igualdad de trato entre los licitadores y de transparencia».

Esto significa que la existencia de un conflicto de intereses -que exige acreditación suficiente- no significa de modo automático la necesidad de su exclusión del procedimiento ni, mucho menos, la declaración de prohibición de contratar con alcance general. La proporcionalidad exigible a esta decisión impone a la Administración la obligación de justificar de forma indubitada que es la única opción jurídica posible para proteger adecuadamente los intereses públicos en juego".

53 La nueva redacción de la función del perfil de contratante ex artículo 63 LCSP indica claramente la vocación de los mismos para conseguir una efectiva transparencia y rendición de cuentas de la actividad contractual. 
que el apartado 3 de este precepto obliga a que la publicación de anuncios y otra información relativa a los contratos en los perfiles de contratante surtirá los efectos previstos en la presente Ley cuando los mismos estén alojados en la Plataforma de Contratación del Sector Público o en los servicios de información similares que se establezcan por las Comunidades Autónomas o las Ciudades Autónomas de Ceuta y Melilla. Y la no publicación en la Plataforma comportará la existencia de un vicio de nulidad de pleno derecho (supuesto regulado de forma expresa en el artículo 39.2 c) LCSP).

El acceso a los pliegos y demás documentación complementaria debe ser por medios electrónicos a través del perfil de contratante, acceso que será libre, directo, completo y gratuito, y que deberá poder efectuarse desde la fecha de la publicación del anuncio de licitación o, en su caso, del envío de la invitación a los candidatos seleccionados.

9. Se mejora también la transparencia en los procedimientos. En el procedimiento «simplificado» del contrato menor se rebajan cuantías y se imponen ciertas reglas con el fin de evitar su indebida utilización (ahora muy «intensiva» en algunas administraciones) para evitar que sirva de cobertura en la práctica de fragmentación del objeto para eludir los controles (articulo 118 LCSP). Asimismo, se obliga a reportar la información de los contratos menores asociado a cada contratista, con el fin de «descubrir» actuaciones irregulares y se limita al importe del contrato menor los contratos que puede obtener un mismo licitador por este procedimiento (opción que supone un «cerco» al contrato menor con la intención de cambiar el modelo práctico de gestión contractual hacia la mayor transparencia).

Existe, además, una novedosa regulación del procedimiento negociado con más detalle (artículos 166 a 168 LCSP). Así, se advierte que existe obligación de negociar, delimitando la ponderación de los distintos aspectos a negociar. Pero lo más destacado es que desaparece el supuesto de procedimiento negociado sin publicidad por la cuantía (con la evidente intención de evitar opacidad y los supuestos de corrupción).

Existe, además, una novedosa regulación del procedimiento negociado con más detalle (artículos 164 a 169). Así, se advierte que existe obligación de negociar, delimitando la ponderación de los distintos aspectos a negociar (y la ausencia de negociación se considera causa de nulidad, como ha indicado Acuerdo del TACPA 8/2015). Pero lo más destacado es que desaparece el supuesto de procedimiento negociado sin publicidad por la cuantía (con la evidente intención de evitar opacidad y los supuestos de corrupción). Opción que se explica de forma expresa en la Exposición de Motivos:

"Con independencia de las normas llamadas a facilitar la lucha contra el fraude y la corrupción, se incluyen nuevas normas tendentes al fomento de la transparencia en los contratos. Así, debe mencionarse, entre otras cuestiones, la introducción de una novedad significativa: la supresión del supuesto de aplicación del procedimiento negociado sin publicidad por razón de cuantía.

Dicho procedimiento, muy utilizado en la práctica, resultaba muy ágil, pero adolecía de un déficit de transparencia, al carecer de publicidad, corriendo el riesgo de generar desigualdades entre licitadores. Para paliar estas deficiencias, se crea en la Ley un nuevo procedimiento de adjudicación, el denominado Procedimiento Abierto Simplificado, ya citado anteriormente al aludirse a los procedimientos de adjudicación, en el que el proceso de contratación está concebido para que su duración sea muy breve y la tramitación muy sencilla, pero sin descuidar, sin embargo, las necesarias publicidad y transparencia en el contrato» ${ }^{54}$.

Interesa destacar que el artículo 159 LCSP introduce el procedimiento abierto con tramitación simplificada (muy similar al de la Ley 3/2011 de Aragón). Los umbrales para su utilización son los no armonizado en suministros y servicios y 2 millones en obras. (salvo poder adjudicador no Administración pública, que lo puede utilizar para todo importe). Este procedimiento, llamado a convertirse en el procedimiento ordinario en estos umbrales, sólo se podrá emplear si los criterios de adjudicación dependientes de juicios de valor no alcanzan determinado porcentaje de la valoración final ${ }^{55}$. Este procedimiento, contempla, además, en su

54 Esta opción de eliminar la posibilidad de negociación por la cuantía, ha sido implantada en Cataluña mediante el Decreto Ley 3/2016, de 31 de mayo, de medidas urgentes en materia de contratación pública (artículo 7). Este Decreto Ley tiene por objeto establecer medidas en relación con la aplicación de determinadas disposiciones de la Directiva 2014/23/UE, del Parlamento y del Consejo, de 26 de febrero, relativa a la adjudicación de contratos de concesión, y la Directiva 2014/24/UE, del Parlamento y del Consejo, de 26 de febrero, sobre contratación pública y por la cual se deroga la Directiva 2004/18/CE. Como consecuencia de la Recomendación de Decisión del Consejo de la Unión Europea de 27 de julio de 2016, por la que se formula una advertencia a España para que adopte medidas dirigidas a la reducción del déficit, se ha presentado la proposición de Ley de medidas para promover la transparencia en la contratación pública -Grupo Parlamentario Popular-, en el Congreso, 21 octubre de 2016.

55 Esta opción, cuestionada por algunos, encuentra justificación en el Informe de la Junta Consultiva de Contratación Administrativa de Aragón 15/2011 de 8 de junio, donde, al analizar el procedimiento con tramitación simplificada introducido por la Ley aragonesa 3/2011, de medidas de Contratos del Sector Público, opina que los criterios de valoración, atendiendo a la finalidad de esta tramitación 
apartado 6, una tramitación «sumaria» en importes inferiores a 80000 euros en obras y 35000 euros en servicios ${ }^{56}$. Con este procedimiento, y sus exigencias formales de presentación en el registro del órgano de contratación y de estar inscrito en el Registro de contratistas se ofrece un ámbito de aplicación más favorables a las PYMEs.

10. Los criterios de adjudicación se vinculan a la lógica de calidad-precio. Los artículos 131.2145 .1 LCSP indican que la adjudicación se realizará ordinariamente utilizando una pluralidad de criterios de adjudicación basados en el principio de mejor relación calidad-precio y desaparece la mención de la «oferta económicamente más ventajosa». Se utiliza, por tanto, el componente cualitativo de la prestación como elemento para decidir la oferta más ventajosa. El cambio es de gran relevancia y explica la nueva regulación del artículo 146 ya no incluya el concepto precio como concepto principal sino el de costes o rentabilidad, así como que se ponga en valor los servicios intelectuales (opción reclamada desde los servicios de ingeniería y arquitectura).

Se precisa (artículo 145.5 LCSP) que los criterios de adjudicación, que deben cumplir los siguientes requisitos: a) deberán estar vinculados al objeto del contrato; ser formulados de manera objetiva, con pleno respeto a los principios de igualdad, no discriminación, transparencia y proporcionalidad; no conferirán al órgano de contratación una libertad de decisión ilimitada; y deberán garantizar la posibilidad de que las ofertas sean evaluadas en condiciones de competencia efectiva.

Hay una doble distinción de criterios: Criterios relacionados con coste (se incluye mejor relación costeeficacia) y criterios cualitativos que permitan identificar la oferta que presenta la mejor relación calidad-precio.

Se limita el uso criterio mejoras, pues no podrá asignársele una valoración superior al 2,5\% y se definen con claridad, para evitar un "uso incorrecto», como las prestaciones adicionales a las que figuraban definidas en el proyecto y en el Pliego de Prescripciones Técnicas, sin que aquéllas puedan alterar la naturaleza de dichas prestaciones ${ }^{57}$.

Entre los criterios adjudicación se incluye, además, la definición y cálculo del coste del ciclo de vida ${ }^{58}$.

Se regulan criterios de desempate (conforme a criterios sociales). Se recuerda la obligación de establecer la ponderación relativa atribuida a cada uno de los criterios de valoración, que podrá expresarse fijando una banda de valores con una amplitud máxima adecuada (la elección de las fórmulas se tendrá que justificar en el expediente. La regulación de la anormalidad de oferta (artículo 149 LCSP) permite poner en valor la calidad de la prestación (y evitar precarización de las condiciones laborales). Anormalidad que supone en todo caso una presunción que debe decidirse posteriormente sobre el criterio de riesgo de incorrecta ejecución de la prestación del contrato. Se exige, pues, de un debate contradictorio a fin de que el licitador pueda probar que su oferta es viable y está destinada a evitar la arbitrariedad del poder adjudicador y garantizar una sana competencia entre las empresas (Sentencia del Tribunal de Justicia de la Unión Europea de 29 de marzo de 2012, SAG EV Slovensko a.s. $)^{59}$.

La nueva regulación permite adoptar una visión distinta sobre la posibilidad de incorporar criterios sociales como criterios de valoración de las proposiciones. En la consideración de la vinculación de los criterios

simplificada, deben ser preferentemente de aplicación matemática, pues el "simplificado» no es más que el procedimiento abierto descargado de algunos trámites procedimentales, por lo que a juicio de la citada Junta no cabría utilizar esta tramitación simplificada en contratos de compleja valoración.

56 No podrá adjudicarse a través de esta modalidad de procedimiento los contratos que tengan por objeto prestaciones de carácter intelectual, lo que resulta totalmente coherente con limitación de la utilización de criterios dependientes de juicios de valor. Como dispone el artículo 159.6 b) LCSP, se eximirá a los licitadores de la acreditación de la solvencia económica y financiera y técnica o profesional. Ahora bien, lo que no se exime de forma expresa es la obligación de acreditar la personalidad, representación y declaración de no incursión en prohibición de contratar, compromiso de constitución de UTE y sometimiento a fuero español.

57 En todo caso, en el diseño o aplicación de estos criterios deberá analizarse la existencia de prácticas calificadas como red flags, tales como que exista un único licitador (criterio aplicado por el Tribunal de Contratos Públicos de Aragón en su Acuerdo 60/2015, de 15 de mayo), que podrán justificar la anulación de la licitación.

58 Vid. R. DELGADO FERNÁNDEZ, "El cálculo del coste del ciclo de vida en la contratación administrativa", Revista Gabilex, núm. 7, 2016, págs. 116-152. Como destaca esta autora, «Su aplicación práctica presenta ciertamente problemas, que disminuirán según se avance en su aplicación y aumenten los conocimientos al respecto de los gestores de contratación y que solo se podrán resolver con la voluntad decidida de las administraciones contratantes. Sin duda dicha aplicación experimentará un estímulo importante si se aprueban normas de cálculo generales en el ámbito de toda la UE. Ya existen antecedentes (sobre todo en la industria militar y de la construcción) de dicho cálculo y normas internacionales que analizan y calculan el ciclo de vida desde diferentes aspectos y pueden ayudar a la aplicación del mismo como criterio de valoración así como proyectos en marcha sobre este aspecto».

59 En el supuesto de presunción de anormalidad se debe solicitar a la empresa afectada una aclaración de los elementos en que el licitador fundamentó su oferta y en la verificación de que, conforme a dicha aclaración, la misma es viable, de forma que la ejecución de la prestación que constituye el objeto del contrato queda garantizada, en el modo y manera establecidos en los pliegos de condiciones. Por todos, Acuerdo 9/2017 del Tribunal Administartivo de Contratos Públicos de Aragón. 
sociales resulta de especial interés la doctrina recogida en la STJUE de 10 de mayo de 2012, en el Asunto C-368/10, que señala que «no es necesario que un criterio de adjudicación se refiera a una característica intrínseca de un producto, es decir, a un elemento incorporado materialmente en este», y que concluye que "nada se opone, en principio, a que dicho criterio se refiera al hecho de que un producto proceda del comercio justo ${ }^{60}$. En todo caso, debe exigirse tanto que la elección de los criterios esté presidida por la satisfacción del interés público que persigue todo contrato, de manera que los mismos han de ser coherentes con el objeto, las características y la propia naturaleza del contrato, como que no se desvirtúen los propios principios de la contratación pública.

En ciertas ocasiones la estrategia social del contrato aconseja prestar especial atención a la fase de ejecución, mediante condiciones especiales de ejecución (artículo 202 LCSP) que serán obligatoria para todo licitador que aspire a la adjudicación. Regular las retribuciones mínimas del personal y su forma de acreditación periódica, prever la obligación de subcontratación de ciertos elementos del contrato con determinados colectivos sociales (como empresas de iniciativa social), imponer penalidades contractuales que «estimulen» el correcto cumplimiento de la sensibilidad social del contrato, son, entre otras, previsiones muy eficaces en la consolidación de una contratación socialmente responsable eficaz (sin obviar el importante efecto didáctico para extender estas propuestas al sector privado).

Las condiciones especiales de ejecución pueden ser el «vehículo» más idóneo para implementar políticas sociales o ambientales, tal y como ya ha advertido el Tribunal de Contratos Públicos de Aragón en su Acuerdo 72/2016, donde, con relación a la exigencia de mantener la retribución de los trabajadores durante la ejecución del contrato, este Tribunal administrativo considera legal tal opción, ya que entiende que «no limita la competencia ni interfiere en la opción de gestión del contrato, y que pretende dotar de calidad a la prestación del contrato, evitando la precarización de condiciones laborales como justificación de rebaja de precios en las ofertas, lo que casa mal con la obligación de calidad/precio que refiere el artículo 67 de la Directiva 2014/24/UE, de contratación pública. Justifica su argumento en la citada Sentencia TJUE de 17 de noviembre, Regio Post (asunto C-115/14), en tanto permite garantizar la correcta prestación del contrato. Y recuerda que el licitador que oferta conforme a las condiciones de un convenio colectivo, está obligado a mantener esas condiciones por cuanto la oferta es parte del pliego y los pliegos son lex contractus que vinculan durante su ejecución conforme al principio pacta sunt servanda, sin que la ultraactividad de los convenios pueda interferir en la ejecución de un contrato ya adjudicado, pues se quebraría el principio de equivalencia de las prestaciones, así como el principio de igualdad de trato entre licitadores, al alterarse las condiciones de la adjudicación» ${ }^{61}$.

11. El régimen de modificación del contrato (artículos 203 a 206 LCSP), que mantiene la distinción entre modificados convencionales y supuestos no previstos en el pliego, es más restrictivo que el que establecen las nuevas Directivas comunitarias, con la finalidad de evitar prácticas irregulares (no en vano el considerando 107 de la Directiva de contratación pública recuerda que es de directa aplicación la jurisprudencia europea sobre esta materia) ${ }^{62}$. Se introduce por ello adverbio "solo», con la finalidad de remarcar el carácter excepcional de la modificación y se limitan ciertas posibilidades ${ }^{63}$. No hay modificados de «minimis». En todo caso, la jurisprudencia del TJUE sobre esta materia sigue siendo de aplicación (considerando 107 de la Directiva 2014/24).

60 Vid. T. MEDINA, "La contratación pública socialmente responsable a través de la jurisprudencia del Tribunal de Justicia de la Unión Europea", REDA, núm. 153, 2012, págs. 213-240.

61 No es posible una cláusula social, ni como condición de ejecución, que prevea que una empresa adjudicataria repercuta los beneficios derivados del contrato (o tribute por ellos) en un concreto territorio, por ser claramente discriminatoria (Informe 15/2016, JCCA de Aragón). Ni tampoco son admisibles los criterios de arraigo (el Informe de la Junta Consultiva de Contratación Administrativa del Estado 9/2009, de 31 de marzo, advierte de la no validez). El Tribunal Administrativo Central de Recursos Contractuales, en su Resolución 130/20154, ha declarado la nulidad del criterio social, porque precisaba que las personas desempleadas fueran demandantes de empleo en oficinas concretas circunscritas a una Comunidad Autónoma.

62 La efectividad del principio de concurrencia exige una interpretación restrictiva a esta posibilidad-entendida como una potestad condicionada- en la que, en tanto parte del procedimiento de adjudicación, debería darse trámite de audiencia a todos los licitadores interesados en ese contrato, dando posibilidad a su impugnación en caso de entenderse incorrecta la modificación efectuada vid. J. L. MEILAN GIL, La estructura de los contratos públicos, ob. cit., pág. 243. También BAÑO LEÓN, "Del ius variandi a la libre concurrencia: la prohibición de modificación como regla general de los contratos públicos", Anuario de Gobierno Local 2012, IDP, Barcelona, 2013, págs. 142-145

63 En ningún caso los órganos de contratación podrán prever en el pliego de cláusulas administrativas particulares modificaciones que puedan alterar la naturaleza global del contrato inicial. En todo caso, se entenderá que se altera ésta si se sustituyen las obras, los suministros o los servicios que se van a adquirir por otros diferentes o se modifica el tipo de contrato. No se entenderá que se altera la naturaleza global del contrato cuando se sustituya alguna unidad de obra, suministro o servicio puntual (204. 2 LCSP). 
Se regula la cesión del contrato con el fin de evitar que se considere modificación contractual. Interesa destacar que toda modificación debe publicarse (artículos 203.3 y 205 LCSP) y notificarse los acuerdos de modificación (opción ya incorporada en Aragón y Navarra) y que, como ya se ha visto, la modificación puede ser objeto de recurso especial ${ }^{64}$. Esta regulación debe interpretarse conforme a los principios de la contratación pública y, para su correcto funcionamiento, parece conveniente, amén de avanzar en la idea de una adecuada planificación y gestión pausada del proyecto que posteriormente favorezca su rápida ejecución sin incidentes, que se regule mejor la responsabilidad de los autores de proyectos y directores de obras -exigiendo el replanteo previo antes de la aprobación del proyecto-y, en general, de todo personal responsable de la ejecución del proyecto ${ }^{65}$.

Hay que resaltar que se ha eliminado la posibilidad del Proyecto de Ley de «libre» modificación en los contratos no armonizados para los poderes adjudicadores no Administración pública-coherente con la regulación del TRLCSP 2011, que obliga con indiferencia del importe-, lo que lamina la posibilidad de descontrol en los sobrecostes y, también, que exista un «incentivo» a crear entes instrumentales para alejarse del control y reglas públicas. Esta decisión incluida ahora en el artículo 317 LCSP de «no facilitar» la modificación contractual en contratos no armonizados de poderes adjudicadores no Administración pública, supone un claro «impulso» en la lógica de uniformidad jurídica y, sobre todo, de la regeneración democrática y la prevención de la corrupción ${ }^{66}$.

12. En el régimen de contratos administrativos existen ajustes técnicos (por ejemplo, mayor plazo garantía en los contratos de obras), más importantes en la regulación de las concesiones: donde se incluye el concepto de la Tasa Interna de Rentabilidad o Retorno (TIR). Se confirma la actual regulación de la responsabilidad patrimonial administrativa en los casos de resolución de las concesiones (RPA), que es un elemento de seguridad importante, que funciona como efecto llamada en los inversionistas al garantizar parte del negocio más allá del riesgo lógico de la gestión de la concesión. La RPA se comporta como un elemento de aseguramiento de ciertos riesgos, pero no puede ser regulada o configurada de modo absoluto pues se diluiría el elemento del riesgo operacional ${ }^{67}$. Esta RPA se limita, para la resolución por causa imputable al

${ }^{64}$ Sobre esta cuestión me remito a J. M. GIMENO FELIU, "Presente y futuro de la regulación de la modificación de los contratos del sector público", libro colectivo Observatorio de los Contratos Públicos 2015, Aranzadi. Cizur Menor, págs. 31-138.

65 Vid. J. M. GIMENO FELIU, "Presente y futuro de la regulación de la modificación de los contratos del sector público", ob. cit., págs. 131-135.

${ }_{66}$ Sin embargo, al Consejo de Estado en su Dictamen al ALCSP de marzo de 2016, de forma sorprendente, le convence esta opción y declara que «Por lo tanto, en comparación con el TRLCSP en vigor, la aplicación de este régimen de modificación contractual está más acotada. En efecto, ya no afecta a todos los contratos del sector público, sino solamente a aquellos sujetos a las directivas europeas. Esta solución resulta razonable y plenamente acorde al origen comunitario de dicho régimen.». La visión de la modificación limitada a una mera exigencia europea y no al ejercicio correcto de los principios de integridad, eficiencia y buen gobierno pone en cuestión una adecuada solución del problema de los sobrecostes en la contratación pública. La dicotomía de regímenes, en función del importe, no parece una solución correcta, en tanto se crean dos regulaciones distintas para situaciones que exigirían una misma solución jurídica.

67 Avala esta interpretación la nueva regulación del SEC (2010), aprobada por el Reglamento (UE) núm. 549/2013 del Parlamento Europeo y del Consejo, de 21 de mayo de 2013, relativo al Sistema Europeo de Cuentas Nacionales y Regionales de la Unión Europea. En relación a cómputo déficit de las operaciones de APP se indica que: "Propiedad económica y asignación del activo 20.283 Al igual que sucede con los contratos de arrendamiento, para determinar quién es el dueño económico de los activos en una APP es preciso averiguar qué unidad asume la mayor parte de los riesgos y qué unidad se espera que reciba la mayor parte de los beneficios de los activos. Se asignará a esta unidad el activo, y por lo tanto la formación bruta de capital fijo. Los principales elementos de riesgo y beneficio que deben evaluarse son los siguientes:

a) Riesgo de construcción, que incluye los rebasamientos en los costes, la posibilidad de costes adicionales derivados de retrasos en la entrega, el incumplimiento de condiciones o códigos de construcción, y los riesgos ambientales y de otros tipos que exijan pagos a terceros.

b) Riesgo de disponibilidad, que incluye la posibilidad de costes adicionales, como los de mantenimiento y financiación, y las sanciones soportadas porque el volumen o la calidad de los servicios no cumple las normas especificadas en el contrato.

c) Riesgo de demanda, que incluye la posibilidad de que la demanda de los servicios sea mayor o menor de la esperada.

d) El riesgo de valor residual y obsolescencia, que incluye el riesgo de que el activo sea inferior a su valor esperado al final del contrato y el grado en que las administraciones públicas tienen opción a adquirir los activos.

e) La existencia de financiación del garante o de concesión de garantías, o de cláusulas de rescisión ventajosas sobre todo en caso de rescisión a iniciativa del operador". Estos dos últimos apartados, en especial en los casos de resolución por causa imputable al contratista parecen aconsejar una "limitación" de la RPA en los modelos concesionales, tanto de obra como de servicios, pues de lo contrario puede entenderse que se ha excluido la transferencia de riesgos y, en consecuencia, los activos ya no estarían excluidos del perímetro de endeudamiento. Así, dentro del riesgo operacional debe entenderse la no existencia de RPA por incumplimientos o causas imputables al concesionario. Sobre la incidencia del nuevo sistema de cómputo de déficit en SEC 2010 puede consultarse el trabajo de A. B. MACHO PÉREZ y E. MARCO PEÑAS, "El impacto de las colaboraciones público-privadas en los niveles de déficit y deuda pública: análisis de los criterios de EUROSTAT”, RAP, núm. 194, 2014, 437-474. 
concesionario, la RPA atendiendo al nuevo criterio SEC 2010 (el pago de la concesión se realizará atendiendo al valor de mercado de la misma) ${ }^{68}$. Se permite pagos por disponibilidad ${ }^{69}$.

Interesa llamar la atención sobre el dato de que la retribución tendrá la condición de tarifa, tanto en los casos de concesión de obras como de concesión de servicios (nuestros «servicios públicos»). Se acoge expresamente la tesis, defendida desde hace mucho tiempo por el profesor J. TORNOS MAS ${ }^{70}$. Lo que obligará a reformular cierta jurisprudencia que, en servicios públicos, opta por la configuración de tasa ${ }^{71}$. Y no es una cuestión sin efectos prácticos pues, como bien advierte J. TORNOS, «la tasa supone recaudación para un gasto público. Esto determinará que el servicio se convierte en un gasto que puede computar a efectos del déficit municipal. De acuerdo con los criterios EUROSTAT en relación con el tratamiento contable de los modelos concesionales, un cambio de modelo como el que se plantea (unido a otros datos adicionales como el compromiso de reversión de las instalaciones a la finalización del contrato), puede implicar que los compromisos de pago adquiridos por el Ayuntamiento por la duración total del contrato consoliden en su contabilidad, a efectos del cálculo del déficit y la deuda». La opción de la Ley, por este motivo es clara: la retribución de la concesión tiene naturaleza jurídica de tarifa (y no puede ser ya de opción por la entidad contratante su configuración como tasa), pues la calificación como ingreso tributario diluye -o anula- la transferencia del riesgo operacional, con efectos desde la perspectiva de consolidación de déficit ${ }^{72}$.

Por otra parte, al regular el reequilibrio económico de la concesión de obras y servicios se mantiene la redacción actual sobre el factum principis (decisión de la Administración pública concedente que incide de forma sustancial en concesión) y no se incorpora como causa de reequilibrio el riesgo imprevisible ${ }^{73}$. Se permite ampliar un 15 por ciento de su duración inicial para restablecer el equilibrio económico del contrato. En el ámbito de los sectores públicos autonómico y local, deberán remitirse al Comité Técnico de Cuentas Nacionales o, todos los contratos de concesión de obras o de concesión de servicios adjudicados en sus respectivos ámbitos, cuyo valor estimado sea igual o superior a doce millones de euros, o cuando, en su financiación se prevea cualquier forma de ayuda o aportación estatal, o el otorgamiento de préstamos o anticipos.

68 En todo caso, se entenderá que es imputable al concesionario la resolución del contrato cuando ésta obedezca a haber sido declarado aquél en concurso o insolvencia en cualquier otro procedimiento. Las concesiones que hayan sido adjudicadas con anterioridad a la entrada en vigor de la Ley o cuyos expedientes de contratación se hayan iniciado con anterioridad a dicha fecha, se regirán por la normativa anterior, es decir, no se verán afectados por la nueva regulación de la RPA.

69 Existen problemas derivados de SEC 2010: ahora es transferencia de riesgo de demanda, o riesgo de oferta, o de ambo (son, pues, distinto a criterios de SEC 95). Sobre la incidencia del nuevo sistema de cómputo de déficit en SEC 2010 puede consultarse el trabajo de A. B. MACHO PERÉZ y E. MARCO PEÑAS, "El impacto de las colaboraciones público-privadas en los niveles de déficit y deuda pública: análisis de los criterios de EUROSTAT", RAP, núm. 194, 2014, 437-474.

70 "La tarifa como forma de retribución de los concesionarios: una figura constitucional y necesaria", El Cronista del Estado Social y Democrático de Derecho, núm. 24, 2011, págs. 22-29.

71 Vid. J. TORNOS MAS, en su excelente artículo "Informe sobre la contraprestación del servicio de abastecimiento domiciliario de agua: La Sentencia del Tribunal Supremo de 23 de noviembre de 2015 (RI§1151068)", Revista Derecho Municipal, lustel, 10 de marzo de 2016. El análisis de la evolución jurisprudencial y las consecuencias prácticas de la distinta calificación refuerzan las conclusiones que propone.

72 La opción de configurar tasa supondría, de hecho, la imposibilidad de impulsar concesiones de servicios. Sirva de referencia el trabajo de J. GARCIA HERNÁNDEZ, "El fin de las concesiones administrativas de gestión de servicios públicos en los supuestos en los que la retribución que abonan los usuarios tengan naturaleza de tasa: ¿y ahora qué?", Revista Derecho Local, núm. 38, febrero de 2016.

73 Esta decisión de no «cambiar» la regulación del factum principis no parece una buena solución. En mi opinión, deben englobar cualquier decisión administrativa (o legislativa) que altere de forma imprevisible el adecuado reparto de riesgos y permita no distorsionar indebidamente la tasa interna de rentabilidad. La concesión se explota por el contratista a riesgo y ventura, de tal manera que el reparto de riesgos pactado no debe ser alterado ni modificado, lo que no impide -más bien lo contrario- el reequilibrio financiero, pues, como ya ha advertido el Consejo de Estado, a propósito del principio de riesgo y ventura, «el fundamento de este principio es triple: en primer lugar, el principio de seguridad jurídica (Dictamen número 50.293, de 5 de noviembre de 1987); en segundo lugar, el principio de concurrencia y la necesidad de no desvirtuar las garantías presentes en la adjudicación de los contratos de las Administraciones Públicas (pues una erosión del principio de riesgo y ventura podría hacer ilusorias las garantías que en la licitación se ofrecieron a aquellos licitadores que no resultaron adjudicatarios), y en tercer lugar, la protección de los intereses de la Hacienda pública» (Dictamen de 13 de marzo de 2003 (Expediente 3.344/2002). No reconocer tal opción para el equilibrio del contrato conllevaría importantes dosis de inseguridad jurídica que condicionarán las inversiones en estos contratos. $Y$ en nada se rompe el principio de igualdad o eficiencia pues permite dar seguridad para garantizar la correcta ejecución del contrato y su plan financiero con independencia de quien resulte adjudicatario. Igualmente debe regularse la cláusula de progreso y su concreto significado obligacional, pues la propia evolución técnica puede conducir a tal desequilibrio que haga inviable la gestión de la concesión, planificada en un entorno de la técnica distinta. Importa promover los avances tecnológicos a toda concesión, pero cuando al inversión afecta a la lógica sobre la que se planificó la inversión debería ajustarse la TIR. Por último, aunque se entienda ahora excluido bien podría regularse los efectos del riesgo imprevisible (lo que evitaría la posterior «judicialización», con las incertidumbres que comporta). Vid. J. M. GIMENO FELIU, EI nuevo paquete legislativo..., ob. cit., págs. $148-150$. 
13. En las prerrogativas de los contratos de concesión de obras y de servicio se mantiene la técnica del rescate como privilegio unilateral de resolución anticipada (que no debe confundirse con supuestos de resolución por incumplimiento o concurso de la empresa concesionaria), si bien se exige que exista interés público y que se acredite que dicha gestión directa es más eficaz y eficiente que la concesional (artículos 279 c) y 294 c) LCSP, según sea concesión de obras o concesión de servicios)

Esta opción incumple formalmente la previsión del artículo 44 la Directiva de concesiones, que establece unos límites a la posibilidad de resolución anticipada por voluntad de la Administración, pues se desnaturaliza la filosofía del régimen de contratación en el ámbito de las concesiones, donde no tiene cobertura, con la extensión hasta ahora utilizada, de las prerrogativas públicas exorbitantes ${ }^{74}$. El interés público -al igual que sucede con la modificación contractual- ya no es título jurídico suficiente para ejercer potestades sobre el contrato. En este sentido resulta de interés la STJUE de 7 de Septiembre de 2016, Frogne, al afirmar que: «el artículo 2 de la Directiva 2004/18 debe interpretarse en el sentido de que, con posterioridad a la adjudicación de un contrato público, no es posible introducir en él una modificación sustancial sin abrir un nuevo procedimiento de adjudicación del contrato, ni siquiera en el supuesto de que esa modificación constituya, objetivamente, una solución de compromiso que implique renuncias recíprocas de ambas partes y pretenda poner fin a un conflicto de resultado incierto, nacido de las dificultades que la ejecución del contrato plantea. Sólo cabría una conclusión diferente en el caso de que la documentación de dicho contrato estableciera la facultad de adaptar determinadas condiciones del mismo, incluso importantes, con posterioridad a su adjudicación y determinara el modo de aplicar esa facultad» ${ }^{75}$. Los ejes de la regulación europea no son las prerrogativas públicas, sino preservar el derecho de la competencia entre operadores y respetar el principio de seguridad jurídica que obliga a estar a lo pactado. El rescate, como tal, es ya expropiación forzosa y no privilegio contractual, y deberá sustanciarse conforme a las reglas y principios de esta potestad (así se reconoce en el Proyecto de Ley de Contratos Públicos de Navarra, en tramitación ${ }^{76}$.

La opción española, en todo caso, desde la perspectiva del resultado, viene a imposibilitar la práctica del rescate, pues la acreditación de mejor eficacia y eficiencia como condicionantes previo para adoptar la decisión se antoja de casi imposible cumplimiento (solo el coste indemnizatorio de la rescisión anticipada impedirá en muchos casos que pueda existir una gestión directa más eficiente) ${ }^{77}$.

14. En materia organizativa destaca la previsión relativa a la mesa de contratación, que se define como órgano de asistencia técnica especializada (lo que supone que no puede tener componente político en las personas que se designan, tal y como advirtiera el Tribunal Administrativo de Contratos Públicos en su Acuerdo 45/2013, de 7 de agosto). Se regulan los órganos de contratación de las entidades locales (sin especiales novedades). Debe mencionarse la nueva regulación de la figura del perfil de contratante, más exhaustiva que la anterior, que le otorga un papel principal como instrumento de publicidad de los distintos actos y fases de la tramitación de los contratos de cada entidad. Pero a efectos de publicidad/transparencia debe estarse a la publicidad en Portal Contratación Sector Público (o autonómicos, interconectados). Los plazos de presentación de solicitudes se inician en momento publicación en la Plataforma de Contratos del Sector Público. El Boletín oficial no es ya obligatorio y será gratuito. Existe, además, una nueva regulación del Registro de Contratos del Sector Público (que debe servir para mejorar no solo en simplificación, sino también en transparencia), en el que se inscribirán todos los contratos adjudicados por las entidades del sec-

74 Vid. J. M. GIMENO FELIU, "Remunicipalización de servicios locales y Derecho comunitario", Revista El Cronista del Estado Social y Democrático de Derecho, núms. 58/59, 2016, págs. 50-71 (ibídem, "La remunicipalización de servicios públicos locales: la necesaria depuración de conceptos y los condicionantes jurídicos desde la óptica del derecho europeo", Cuadernos de Derecho Local, núm. 43, 2017). Opinión que comparte el profesor J. TORNOS MAS, "La remunicipalización de los servicios públicos locales. Algunas precisiones conceptuales", El Cronista del Estado Social y Democrático de Derecho, núms. 58-59, 2016, pág. 49. Sobre esta cuestión es de especial interés el libro Servicios Públicos e ideología. El interés público en juego (F. CAAMAÑO, J. M. GIMENO, P. SALA y G. QUINTEROS), Profit, 2017, págs. 87-90.

75 El Tribunal considera que es indiferente que la modificación se deba más a la voluntad de superar un conflicto que a la de renegociar las condiciones de la contratación. E insiste en la necesidad de respetar los principios de igualdad de trato y la obligación de transparencia.

76 Sirva de ejemplo la Legislación de Puertos (Real Decreto Legislativo 2/2011, de 5 de septiembre, por el que se aprueba el Texto Refundido de la Ley de Puertos del Estado y de la Marina Mercante), donde al prever el rescate de las concesiones (de dominio público) se regula tal posibilidad no como prerrogativa sino como procedimiento ablatorio (artículo 99).

77 Sobre la necesidad de adecuada motivación en estos procesos me remito a J. PONCE, "Remunicipalización y privatización de los servicios públicos y derecho a una buena administración. Análisis teórico y jurisprudencial del rescate de concesiones", Cuadernos de Derecho Local, núm. 40, 2016, pág. 80. Por ello, no es aceptable, por ejemplo, que un simple cambio de mayorías políticas en un gobierno local conduzca a fundamentar el rescate por razones, digamos, ideológicas. 
tor público, siendo obligatoria, a dichos efectos, la comunicación de los datos relativos a todos los contratos celebrados por importe igual o superior a cinco mil euros.

15. En relación al recurso especial conviene reseñar la extensión del recurso especial a cuantías inferiores a las del importe armonizado, es una decisión muy destacada, pues ha de ayudar corregir las debilidades detectadas de nuestro modelo de contratación pública ${ }^{78}$. La opción contenida en el proyecto de Ley limitaba «en exclusiva» este recurso especial a los contratos de importe armonizado. Opción cuestionada por la doctrina de forma unánime ${ }^{79}$. Y también por órganos cualificados como el Consejo de Estado ${ }^{80}$, Comité Económico y Social ${ }^{81}$, Comisión Nacional de los Mercados y la Competencia ${ }^{82}$ o Transparencia Internacional España ${ }^{83}$. El cambio producido es muy relevante pues implica superar la visión del recurso especial como una carga burocrática o "gasto» innecesario, para configurarse como un instrumento que permita garantiza la mejor transparencia mediante una estrategia del control preventivo que sea efectivamente útil, rápido, e independiente, vinculado al derecho a una buena administración y no a las prerrogativas de la Administración ${ }^{84}$. La opción de rebajar umbrales es, sin duda, un hito en la filosofía práctica de la contratación pública, y debe ser el inicio de un proceso para, tras dotar con medios y recursos a los órganos de recursos contractuales, extender al recurso especial a cualquier contrato al margen del importe ${ }^{85}$. Por ello, resulta muy relevante la opción de ampliar por el importe el recurso especial frente a su limitación inicial a los contratos armonizados, que supera una extendida perspectiva de "gasto», y no de inversión, cuando se analizan

78 Debe recordarse que la Resolución del Parlamento Europeo, de 25 de octubre de 2011, sobre la modernización de la contratación pública (2011/2048(INI)), subraya que se debe evitar la introducción de nuevas normas para los mercados de contratación pública que no alcancen los umbrales de la UE, ya que se puede poner en peligro la seguridad jurídica establecida a escala nacional.

79 Conviene recordar el trabajo de J. A. MORENO MOLINA "Un mundo para SARA, una nueva categoría en el Derecho español de la contratación pública, los contratos sujetos a regulación armonizada", $R A P$, núm. 178, 2009, págs. 175-213. Con la positivización de esta categoría se pretende, en suma, modelar la aplicación de las normas de la Directiva en los diferentes contratos del sector público, restringiéndola solo a los casos exigidos por dicha norma y diseñando para los demás, como declara la Exposición de Motivos un régimen par el que el legislador nacional tiene plena libertad. Y es que, como bien afirma J. M. BAÑO LEÓN, no cabe que un concepto de la legislación de contratos públicos se interprete de una forma cuando el contrato está condicionado por las Directivas comunitarias que cuando no lo está. "La influencia del Derecho comunitario en la interpretación de la Ley de Contratos de las Administraciones Públicas", $R A P, 151,2000$. pág. 13. Opinión que comparte E. CARBONELL PORRAS en su trabajo "El título jurídico que habilita el ejercicio de la actividad de las sociedades mercantiles estatales de infraestructuras viarias. ¿Convenio o contrato administrativo?", en libro colectivo Estudios de Derecho Público Económico, Civitas, Madrid, 2003, pág. 392.

80 Dictamen 514/2006, de 25 de mayo. Afirma lo siguiente: "La primera duda que plantea la regulación proyectada para el nuevo recurso especial y el nuevo sistema especial de medidas provisionales radica en su ámbito de aplicación. Con arreglo a los artículos 37.1 y 38.1 del anteproyecto, tales mecanismos son únicamente aplicables en los procedimientos de adjudicación de contratos sujetos a regulación armonizada, por lo que no se extenderán a los restantes contratos del sector público. A juicio del Consejo de Estado, esta distinción entre los mecanismos de control de uno y otro tipo de contratos no está suficientemente justificada y podría generar un cierto nivel de inseguridad jurídica, por lo que debería considerarse su extensión a todos los contratos.

La finalidad que se persigue con el nuevo recurso y el sistema especial de medidas cautelares es, en último término, garantizar que el control del procedimiento de adjudicación sea rápido y eficaz, de modo que las incidencias que pueda plantearse se tramiten y resuelvan antes de adoptarse la decisión de adjudicación. Esa conveniencia de rapidez y eficacia en la resolución de las incidencias del procedimiento de adjudicación resulta extensible a cualquier tipo de contrato, esté o no sujeto a regulación armonizada. Así se ha hecho en el Derecho francés, cuyo référé précontractuel, aunque creado en cumplimiento de la normativa comunitaria, se extiende al control de la observancia de las reglas de publicidad y concurrencia de todos los contratos, estén o no en el ámbito de aplicación de las directivas. Frente al ejemplo francés, otros países, como Alemania, han optado por restringir la aplicación de esta vía especial de recurso a los contratos sujetos a la regulación comunitaria, una solución a la que nada hay que oponer desde el punto de vista del cumplimiento de las normas comunitarias, pero que sin duda resulta menos garantista para los administrados".

81 DICTAMEN núm. 8, 2015, sesión ordinaria del pleno 25 de junio de 2015.

82 IPN/CNMC/010/15 (Informes de Propuestas Normativas).

${ }^{83} \mathrm{En}$ el documento sobre Medidas de transparencia y prevención de la corrupción en Subvenciones, Licitaciones y Contratos públicos, de octubre de 2015 (medida III.- 2), se insiste en la necesidad de extender el recurso al mar gen del importe (http://transparencia.org.es/ti-espana-propone-a-los-partidos-politicos-60-medidas-contra-la-corrupcion-en-subvenciones-licitaciones-y-contratos-publicos-2/)

${ }^{84}$ Vid. J. M. GIMENO FELIU, Sistema de control de la contratación pública en España. (cinco años de funcionamiento del recurso especial en los contratos públicos. La doctrina fijada por los órganos de recursos contractuales. Enseñanzas y propuestas de mejora), número monográfico especial (2016), Observatorio de los contratos Públicos, Aranzadi, Cizur Menor, 2016.

85 Como bien ha destacado el Profesor J. M. BAÑO LEÓN, el sistema de recursos administrativos ordinarios no está configurado en clave de protección de la legalidad, pues pretende proteger a la Administración. De hecho, como bien explica, el sistema de justicia administrativa es un ejemplo de la inercia autoritaria del Derecho Público español. Por ello, como bien afirma, «la mejor alternativa al recurso administrativo es un buen recurso administrativo, entendiendo por tal el que garantiza una revisión de la actuación administrativa eficiente por un órgano funcionalmente independiente». "El recurso administrativo como ejemplo de la inercia autoritaria del Derecho Público español", en libro colectivo Las vías administrativas a debate, INAP, 2016, pág. 669. Con esta ampliación del ámbito del recurso especial desde la perspectiva del importe se avanza en la filosofía del régimen equivalente en el nivel de eficacia exigido por STJUE de 6 de octubre de 2015, Orizzonte Salute, C- 61/14. 
los escenarios preventivos de control eficaz ${ }^{86}$. Se extiende el objeto del recurso contra modificaciones y encargos ilegales (lo que supone que ya no es recurso precontractual) ${ }^{87}$. Sin embargo, a mi juicio de forma errónea, no se incluyen en su objeto, pese a ser obligación europea, ni las alteraciones de las condiciones de subcontratación, así como los supuestos de resolución de los contratos (aunque se introduce dentro del objeto del recurso especial los rescates de concesiones). Esta limitación objetiva no es coherente con las obligaciones derivadas de las Directivas «recursos» vigentes en su nueva redacción derivada de la reforma de 2014. Previsiones que, por cierto, tienen efecto directo, como ha recordado la Sentencia del Tribunal de Justicia (Sala Cuarta) de 5 de abril de 2017, Marina del Mediterráneo SL y otros contra Agencia Pública de Puertos de Andalucía), que aplica un criterio amplio de «decisión» a efectos del ámbito material del recurso especial ${ }^{88}$.

Además, se mantiene el modelo de los tribunales administrativos (cuyas ventajas ha destacado el profesor J. SANTAMARÍA PASTOR ${ }^{89}$ ). Este sistema de «justicia administrativa especial» ha sido reforzado por el hecho de que el Tribunal de Justicia de la Unión Europea admitió a trámite la cuestión prejudicial presentada por el Tribunal Catalán de Contratos del Sector Público en fecha 23 de julio de 2014 (asunto C-203/14), lo que presupone reconocer que estos Tribunales administrativos -con fundamento en la Directiva 89/665 y su reforma por Directiva 66/2007-, tienen la calificación de órganos jurisdiccionales por cuanto tienen origen legal, tienen carácter de permanentes, aplican un procedimiento contradictorio aplicando las normas jurídicas y son independientes (Sentencia de 17 de septiembre de 1997, asunto C-54/96 Dorsch Consult). Y así se ha declarado por la sentencia TJUE de 6 de octubre de 2015, Consorci Sanitari del Maresme, C-203/14, que reconoce las notas exigidas para tal consideración -carácter contradictorio del procedimiento, independencia, y carácter obligatorio de su jurisdicción- y declara que los órganos de recursos contractuales de España son órgano jurisdiccional en el sentido del artículo 267 TFUE ${ }^{90}$.

Desde la perspectiva del procedimiento, se mejoran los aspectos de invalidez y desaparece cuestión de nulidad contractual que se integra en el recurso especial. Se reconoce una legitimación amplia conforme doctrina tribunales administrativos (se entiende que incluye doctrina del Tribunal Constitucional sobre la legitimación de concejales, tal y como contempla expresamente el Real Decreto 814/2015, de 11 de septiembre, por el que se aprueba el Reglamento de los procedimientos especiales de revisión de decisiones en materia contractual y de organización del Tribunal Administrativo Central de Recursos Contractuales ${ }^{91}$. No obstante,

86 J. PONCE SOLE, Deber de buena administración y derecho al procedimiento administrativo debido. Las bases constitucionales del procedimiento administrativo y del ejercicio de la discrecionalidad, Lex Nova, Valladolid 2001, pág. 480. Este derecho fundamental a una buena administración se recoge también en la Ley Orgánica 1/2008, de 31 de julio, por la que se autoriza la ratificación por España del Tratado de Lisboa, por el que se modifican el Tratado de la Unión Europea y el Tratado Constitutivo de la Comunidad Europea, firmado en la capital portuguesa el 13 de diciembre de 2007 (artículo 41). Obviamente, las Comunidades Autónomas, en el ejercicio de sus competencias de organización podrán extender el ámbito de este recurso especial a importes inferiores, pues el artículo 112 de la Ley 39/2015, de Procedimiento Administrativo Común (al igual que su predecesora Ley 30/1992, en su artículo 107) habilita tal posibilidad. Así se ha hecho en Aragón mediante la Ley 3/2011, de 24 de febrero, de medidas en materia de Contratos del Sector Público en Aragón, (en redacción dada por la disposición final segunda de la Ley 5/2017, de 1 de junio, de Integridad y Ética Públicas) que fija en 200000 euros el umbral del recurso especial para el contrato de obras y en 60000 euros para los contratos de servicios y suministros.

87 Sobre en carácter no precontractual del recurso especial puede verse mi trabajo La modificación de los contratos: Límites y derecho aplicable", en libro colectivo La contratación pública: problemas actuales, Consejo Consultivo de Madrid, $2013,99.83-140$.

88 La Directiva de concesiones incorpora un supuesto tasado de causas de resolución anticipada cuyo no cumplimiento por una Administración o poder adjudicador abre la puerta al recurso especial. Me remito a mi trabajo "La remunicipalización de servicios públicos locales: la necesaria depuración de conceptos y los condicionantes jurídicos desde la óptica del derecho europeo", Cuadernos Derecho Local, núm. 43, 2017, págs. 50-71. También en el estudio El interés público y su satisfacción con la colaboración público-privada. Fundamentos, equilibrios y seguridad jurídica, Cámara de Comercio de Barcelona, 2017 /J. M. GIMENO, P. SALA y G. QUINTEROS).

89 Lo explica de forma muy clara en su monografía Los recursos especiales en materia de contratos del Sector Público, Aranzadi, Cizur Menor, 2015, en especial, págs. 48-64.

90 E. HERNAEZ SALGUERO, ya había defendido este carácter «cuasi jurisdiccional». "El recurso administrativo especial en materia de contratación a la luz de las resoluciones dictadas por el Tribunal Administrativo de Contratación Pública de la Comunidad de Madrid", Revista Parlamentaria de la Asamblea de Madrid, núm. 28, 28 de junio de 2013, pág. 88. Igualmente, M. J. SANTIAGO, "Los tribunales administrativos de recursos contractuales como mecanismos de control en la contratación pública. Perspectiva actual y de futuro", Revista Auditoría Pública, núm. 66, 2015, págs. 105-118. Este reconocimiento de órgano jurisdiccional a efectos del derecho comunitario, tiene especial consecuencia en lo relativo al obligado cumplimiento de sus Acuerdos o resoluciones, que tiene el carácter de ejecutivos y ejecutorios. Aspecto sobre el que interesa dar cuenta de la Sentencia del Tribunal Supremo de 23 de octubre de 2014 , en el recurso de casación núm. 3014/2013 (asunto de la Privatización Aguas Ter-Llobregat en Cataluña).

91 La legitimación no puede ser un obstáculo para analizar la legalidad de un procedimiento contractual, siempre que se acredite un interés directo y no una mera expectativa. El recurso especial debe interpretarse desde la lógica del artículo 24 CE confiere a todas las personas -personas físicas o personas jurídicas- el derecho a acceder a un tribunal (u órgano independiente de control) para interesar la protección de sus derechos e intereses legítimos individuales o colectivos, lo que obliga a interpretar las normas procesales 
esta ampliación no comporta el reconocimiento a la acción pública, a mi juicio justificada porque la contratación pública guarda directa relación con el derecho a una buena administración ${ }^{92}$.

Hay un nuevo sistema de impugnación plazos de los pliegos (que incorpora la doctrina de la Audiencia Nacional). Las comunicaciones son electrónicas en todo caso. Se elevan las multas por temeridad o mala fe en la interposición del recurso a 30000 euros $^{93}$. Los diferentes órganos de recurso que sean creados acordarán las fórmulas de coordinación y colaboración más adecuadas para favorecer la coherencia de sus pronunciamientos y para la unificación de su doctrina en relación con las cuestiones que sean sometidas a su conocimiento. Dichos órganos podrán además proponer los ajustes normativos y recomendaciones que resulten pertinentes para un mejor funcionamiento de los mecanismos de recurso previstos en la normativa sobre contratos públicos (Disposición Adicional 24).

Se indica expresamente que el recurso es gratuito (lo que elimina la posibilidad de imponer tasas por recurrir) y se mantiene el carácter potestativo. Este carácter potestativo genera evidentes disfunciones procesales, que eran corregidas mediante su consideración de recurso obligatorio en el Proyecto de Ley ${ }^{94}$. Además, la experiencia de independencia del sistema permite vencer la «resistencia» inicial a esta consideración de carácter potestativo, pues su actual funcionamiento ha acreditado que no es una "carga» para el recurrente, sino un remedio procedimental claramente eficaz ${ }^{95}$.

16. De forma acertada, se decide reformar tema jurisdicción superando la dualidad jurisdiccional. Todas las fases de preparación y adjudicación, al margen de importe y naturaleza poder adjudicador, se residencian en el orden contencioso-administrativo. Existe ahora coherencia con la solución adoptada por el actual articulo 2 b) LJ de 1998, que establece la regla (que no debería ser alterada por la legislación de contratos, en tanto legislación sectorial), de que todas las cuestiones de preparación y adjudicación de cualquier poder adjudicador se deben residenciar en sede contenciosa. Es -y debe ser- el criterio funcional de poder adjudicador y no formal de Administración Pública, el que determina ante qué orden jurisdiccional se residencia la

que regulan la atribución de legitimación de forma razonable, en sentido amplio y no restrictivo, con la finalidad de otorgar tutela judicial al administrado y de garantizar la fiscalización del cumplimiento de la legalidad por parte de la Administración (SSTC 28/2005, de 14 de febrero), y 139/2010, de 21 de diciembre). En todo caso, debería avanzarse hacia una legitimación amplia, dado que la verdadera finalidad del control debe ser garantizar el derecho a una buena administración -como recuerda la Directiva 2007/66-. Sobre la legitimación del concejal en el recurso especial, la sentencia del TSJ de Aragón 500/2015, ha recordado que la doctrina del TC es directamente aplicable a este supuesto afirmando que "los razonamientos, que fundamentan la legitimación de los concejales para impugnar en la vía contencioso administrativa los acuerdos municipales en cuya adopción no intervino, sirven igualmente para avalar su legitimación para interponer el recurso especial en materia de contratación previsto en el artículo 40 TRLCSP; sin que su artículo 42, relativo a la legitimación, nos pueda llevar a otra conclusión, precisamente en atención al interés legítimo que ostentan, en los términos establecidos por la doctrina constitucional y jurisprudencial referida; interés -e incluso obligación-, distinto del interés abstracto en la legalidad, de controlar el correcto funcionamiento del Ayuntamiento, como único medio, a su vez, de conseguir la satisfacción de las necesidades y aspiraciones de la comunidad vecinal que, como primera competencia, asigna a los Municipios el art. 25.1 LBRL".

92 J. PONCE, "La prevención de la corrupción mediante la garantía de un derecho a un buen gobierno y a una buena administración en el ámbito local", en Anuario de Derecho Local, 2012, IDP, Barcelona, 2013, págs. 136-137. Esta vinculación de la contratación pública al derecho a una buena administración fue expresamente advertida en el Acuerdo 44/2012, del Tribunal Administrativo de Contratos Públicos de Aragón.

93 Como recuerda la Audiencia Nacional (Sala de lo Contencioso-Administrativo, Sección 4. ${ }^{\text {) }}$ ) en su Sentencia de 14 mayo 2014. JUR 2014\157183, el artículo 47.5. ${ }^{\circ}$ TRLCSP otorga la posibilidad de imponer una multa al recurrente cuando aprecie temeridad o mala fe en la interposición del recurso. La finalidad de esta facultad de imponer una multa no es otra que la de evitar que ese derecho al recurso especial no se utilice de manera abusiva con el fin de dilatar el procedimiento de contratación, teniendo en cuenta que la mera interposición del recurso contra el acto de adjudicación suspende la tramitación del expediente de contratación hasta que el mismo sea resuelto (art. 45 TRLCSP). Obviamente, la denominación de multa no implica que tenga naturaleza sancionatoria, pues su finalidad es de protección del uso adecuado del sistema del recurso especial para conciliar adecuadamente los distintos intereses públicos. Tendría su equivalente en la previsión del artículo 247 de la Ley 1/2000, de 7 de enero, de Enjuiciamiento Civil, sobre respeto a las reglas de la buena fe procesal y multas por su incumplimiento, donde se dice que "si alguna de las partes ha actuado conculcando las reglas de la buena fe procesal, podrán imponerle, en pieza separada, mediante acuerdo motivado, y respetando el principio de proporcionalidad, una multa que podrá oscilar de ciento ochenta a seis mil euros, sin que en ningún caso pueda superar la tercera parte de la cuantía del litigio. Para determinar la cuantía de la multa el Tribunal deberá tener en cuenta las circunstancias del hecho de que se trate, así como los perjuicios que al procedimiento o a la otra parte se hubieren podido causar". Así, es una facultad de carácter procesal del Tribunal administrativo decidir si concurren estas circunstancias de mala fe yo temeridad para imponer la multa.

94 Las explica bien G. MARTÍNEZ TRISTÁN, “¿Es el recurso especial la solución o el problema?”, en libro colectivo La contratación pública: problemas actuales, Consejo Consultivo de Madrid, 2013, págs. 45-54 y P. VALCÁRCEL "Análisis de los rasgos y peculiaridades del recurso especial en materia de contratación pública: en la senda hacia el cumplimiento efectivo del derecho a una buena administración", XI Congreso AEPDA, págs. 27 a 31 de su ponencia (el texto se puede ver en el libro Las vías administrativas de recurso a debate, INAP, Madrid, 2016 (págs. 303 y ss).

95 J. M. GIMENO FELIU, Sistema de control de la contratación publica en España. (cinco años de funcionamiento del recurso especial en los contratos público. La doctrina fijada por los órganos de recursos contractuales. Enseñanzas y propuestas de mejora), número monográfico especial (2016), Observatorio de los contratos Públicos, Aranzadi, Cizur Menor, 2016, pág. 187. 
competencia ${ }^{96}$. Máxime cuando el artículo 2 LJ viene admitiendo la categoría de los actos «materialmente» administrativos. En definitiva, en una actividad como la de los contratos públicos tan sensible desde una perspectiva económica, es necesario dotar a la arquitectura jurídica del control de la necesaria coherencia, que garantice el máximo de seguridad jurídica y favorezca la predictibilidad. Y, por cuanto resulta evidente que en la fase de preparación y adjudicación de cualquier contrato público (incluyendo las modificaciones ilegales), sea o no realizado por una Administración pública, hay un interés público relevante, debe corresponder a la jurisdicción contencioso-administrativa su fiscalización ${ }^{97}$. Desaparece la previsión a arbitraje para los contratos de las Administraciones públicas, para que sea decisión de cada Administración pública.

17. Se diseña un nuevo sistema de gobernanza, del que deriva tanto de un nuevo rol de la Junta Consultiva Contratación Pública (se crea un Comité con representación CC.AA) por exigencia del Derecho de la Unión Europea ${ }^{98}$, como, principalmente, de la creación de un organismo independiente de supervisión y control es la bóveda de una nueva arquitectura institucional para promover las exigencias de gobernanza europea La Oficina Independiente de Regulación y Supervisión de la Contratación está adscrita orgánicamente al Ministerio de Hacienda, pero formada por personal independiente (plazo de 6 años inamovibles), que asume las funciones de Gobernanza de las Directivas de contratación pública ${ }^{99}$. Podrá dictar instrucciones, pero no se le reconocen competencias de "anulación» o sanción ${ }^{100}$. Los poderes adjudicadores tendrán la obligación de transmitir el texto de los contratos celebrados referidos de forma que esta organismo podrá examinarlos y valorar si existen prácticas incorrectas -además de permitir a los interesados acceder a estos documentos, siempre que no resulten perjudicados intereses públicos o privados legítimos- lo que debe contribuir a reforzar la idea de integridad para prevenir supuestos de corrupción y/o clientelismo, que, a la vez que erosionan la idea de objetividad de las Administraciones públicas - que puede conducir a cuestionar su propia legitimidad democrática- conllevan claras y evidentes ineficiencias de los fondos pública ${ }^{101}$. Esta Autoridad independiente se complementa con una Comisión Mixta con el Tribunal Cuentas, de seguimiento de la contratación pública ${ }^{102}$.

\section{CONCLUSIONES}

En el contexto de nuevos retos para la gestión de la contratación pública, configurada como principal herramienta para la implementación de las necesarias políticas públicas y orientada al objetivo de mayor

96 Se explica de forma excelente en el trabajo de P. VALCÁRCEL FERNÁNDEZ y R. FERNÁNDEZ ACEVEDO, "Reivindicación de la competencia del orden contencioso-administrativo para el control jurisdiccional de la contratación del sector público", en libro Observatorio de los Contratos Públicos 2014, Aranzadi, Cizur Menor, 2015, págs. 237-277.

97 Por otra parte, desde la lógica de la arquitectura de los principios procesales sobre los que se fija la competencia, básicamente sujetos y objeto, con causa de interés público, resulta incompresible que el criterio cuantía pueda determinar un cambio de orden jurisdiccional, posibilidad contraria al buen funcionamiento del Estado de Derecho y de la necesaria seguridad jurídica pues la dualidad jurisdiccional en asuntos de misma materia y sujetos quiebra los mismos. Critican por ello, entre otros, la opción del artículo 21 TRLCSP los profs. GARCÍA DE ENTERRÍA y TR. FERNÁNDEZ (Curso Derecho Administrativo, vol. II, 2013, pág. 622).

98 Cuestión en la que insiste la citada Recomendación de Decisión del Consejo de la Unión Europea de 27 de julio de 2016, por la que se formula una advertencia a España para que adopte medidas dirigidas a la reducción del déficit.

99 En todo caso, como bien advierte J. PONCE, la creación de este tipo de unidades no es sino una más de entre las distintas medidas posibles para luchar contra la corrupción, piezas de un puzzle complejo que configura el sistema de integridad de un Estado y condiciona su buen gobierno y buena administración. "Las Agencias anticorrupción. Una propuesta de lista de comprobación en la calidad de su diseño normativo", Revista Internacional Transparencia e Integridad, núm. 3, 2017, pág. 8 de su trabajo. Como advierte, la posible creación de oficinas de este tipo debe ser contextualizada en una estrategia global contra la mala administración y la corrupción y a favor del buen gobierno y la buena administración.

La decisión sobre la creación de una oficina de este tipo debe ponderar, por exigencias del derecho a una buena administración, los costes y beneficios concretos, de todo tipo, que la misma pueda generar, y sólo crearla si los segundos superan a los primeros. Es preciso respetar los principios de buena regulación y la evaluación de impacto normativo exigido ahora por la ley 39/2015.

100 El funcionamiento de la OLAF en la Unión Europea puede servir de ejemplo para su puesta en funcionamiento. Sobre ello resulta interesante el trabajo de M. FUERTES LÓPEZ, "La necesidad de un procedimiento para combatir el fraude (A propósito de las actuaciones de la Oficina europea de lucha contra el fraude, OLAF)", Revista de Administración Pública, núm.175, 2014, págs. 269-301.

101 El titular de la presidencia de la Oficina remitirá a las Cortes y al Tribunal de Cuentas un informe anual sobre las actuaciones y comparecerá en las Cortes para la presentación del informe anual y sus conclusiones.

102 Sin duda puede ser una importante herramienta de apoyo a la función fiscalizadora del Tribunal de Cuentas (y sus homólogos autonómicos), con el fin de controlar legalidad y eficacia (que incluye la fase de ejecución) evitando un incorrecto uso de fondos públi$\mathrm{cos}$, independientemente de la personificación pública o privada que licite en tanto sea poder adjudicador. Vid. A. PEÑA OCHOA, "EI nuevo rol de los organismos de control externo frente a la corrupción”, en libro colectivo La corrupción en España, ob. cit., págs. 83-108. En especial resulta de interés el estudio de J. A. FERNÁNDEZ ASENJO, El control de las Administraciones públicas y la lucha contra la corrupción, Civitas, Cizur Menor, 2011. 
eficiencia, visión estratégica e integridad en la adjudicación de contratos públicos, el legislador español ha acertado (no sin vacilaciones) al revisar en profundidad nuestro modelo jurídico y práctico de la contratación pública, evitando el riesgo de una oportunidad perdida, y apostando por una mejor y mayor transparencia ${ }^{103}$.

La nueva Ley de Contratos del Sector Público de 2017 es compleja y contiene «debilidades» (algunas por inercia). Pero es un avance para reconstruir las «murallas del Derecho Administrativo», concebido como garante del interés general al servicio de los ciudadanos (y de la necesaria transformación social). Lo que puede ayudar a corregir el actual gap entre ciudadanía e instituciones públicas y para asentar el modelo institucional cimentado sobre el buen gobierno. La idea de buen gobierno va más allá de la ausencia de corrupción. Se refiere a unas instituciones transparentes, objetivas y con reglas predecibles para todos, que favorezcan la necesaria seguridad jurídica para que pueda emerger «una economía sana y competitiva». Desde este contexto la nueva Ley de Contratos del Sector Público es una «ventana de oportunidad» para un nuevo liderazgo institucional público a través de una adecuada articulación de la política de contratación pública que, además, puede ayudar en la estrategia de mejorar la productividad de nuestro modelo económico ${ }^{104}$.

103 La invisibilidad de las decisiones explica el fenómeno de la corrupción en un sector tan sensible como el de la contratación pública. Ya lo advertía Platón -cuyas reflexiones continúan siendo de actualidad- en el segundo libro de la República, expone el mito del pastor GIGES. (República, L. II, 359c-360d). En este mito se plantea el dilema moral del hombre, que en caso de poseer un anillo de invisibilidad que le brinda todo el poder para actuar en secreto y con total impunidad, va a actuar, desafortunadamente según muestra la experiencia general, en beneficio propio y de forma deshonesta e injusta.

104 Lo explican GARCÍA SANTANA y coautores, en el estudio Growing like Spain. http://www.garciasantana.eu/Home_files/mis mar 2015-v20.pdf. Idea en la que se insiste en el informe de Ernst \& Young, La crisis del sistema de contratación pública de infraestructuras en España. Razones para el cambio y 25 propuestas de actuación (mayo de 2017), que tiene como objetivo promover un entorno jurídico estable y adecuado en la materia. El informe, identifica los problemas actuales de la contratación pública y advierte que la falta de transparencia y la corrupción están paralizando la inversión pública y dificultando la reactivación económica. 